\title{
Numerical Analysis of Dynamic Response of Corrugated Core Sandwich Panels Subjected to Near-Field Air Blast Loading
}

\author{
Pan Zhang, Yuansheng Cheng, and Jun Liu \\ School of Naval Architecture and Ocean Engineering, Huazhong University of Science and Technology, Wuhan 430074, China \\ Correspondence should be addressed to Jun Liu; hustlj@hust.edu.cn
}

Received 7 May 2014; Accepted 24 August 2014; Published 27 October 2014

Academic Editor: Jeong-Hoi Koo

Copyright ( 2014 Pan Zhang et al. This is an open access article distributed under the Creative Commons Attribution License, which permits unrestricted use, distribution, and reproduction in any medium, provided the original work is properly cited.

\begin{abstract}
Three-dimensional fully coupled simulation is conducted to analyze the dynamic response of sandwich panels comprising equal thicknesses face sheets sandwiching a corrugated core when subjected to localized impulse created by the detonation of cylindrical explosive. A large number of computational cases have been calculated to comprehensively investigate the performance of sandwich panels under near-field air blast loading. Results show that the deformation/failure modes of panels depend strongly on stand-off distance. The beneficial FSI effect can be enhanced by decreasing the thickness of front face sheet. The core configuration has a negligible influence on the peak reflected pressure, but it has an effect on the deflection of a panel. It is found that the benefits of a sandwich panel over an equivalent weight solid plate to withstand near-field air blast loading are more evident at lower stand-off distance.
\end{abstract}

\section{Introduction}

Sandwich panels constructed from light face sheets and relatively low density cores are famous for the powerful ability to support bending load and to save structural weight. The potential advantages of sandwich structures for shock mitigation in both water and air blast have been exploited by some researchers [1-3], but most works were focused on far-field blast, and a less extent study is upon near-field air blast. In the case of far-field blast, shock fronts can be generally treated with acoustic weak shock limit as the shock waves attenuate to a sound wave, and the impulse transmitted to an infinite rigid plate is twice that of incident shock wave due to the complete shock reflection. A classic solution has been built by Taylor [4] to analyze the interaction between acoustic blast wave and free-standing plate, whereas the shock waves are characterized with high intensity and spatially localization in the case of near-field blast. Moreover, the nonlinear compressibility effects of air can further enhance the beneficial effects of FSI to reduce the impulse transmitted to structure [5-7].

Under high intensity blast loading, the mechanical performance of metallic sandwich structures with several topology cores (such as square honeycomb $[8,9]$, triangular honeycomb [10], hexagonal honeycomb [11, 12], and pyramidal lattice [13]) has been investigated. Zhu et al. [8] investigated the failure behaviors of honeycomb core sandwich panel under either uniform or localized air blast loading. Several distinct failure modes were identified. Recent experimental results have revealed that the square honeycomb and pyramidal lattice core sandwich panels suffer significantly smaller back face deflections than solid plates with identical mass when subjected to high intensity air blast loading. It is found that the benefits of square honeycomb core [9] and pyramidal lattice core [13] sandwich panels over monolithic plates diminish when the impulse intensity of shock wave is extremely high. This is due to the complete crush of core webs at the center of panel and the dynamic fracture of front faces (as a result of the high strength of inertially stabilized trusses). Rimoli et al. [14] applied a decoupled wet sand loading model developed by Deshpande et al. [15] to simulate the dynamic response of edge-clamped corrugated core sandwich panels and equivalent weight monolithic plates (made of 6061-T6 aluminum alloy) subjected to wet sand blast loading. A phenomenon of additional face sheet stretching and deflection between corrugation web nodes was observed at high impulsively blast loaded experiments. Then, Wadley et al. [16] used a modified Johnson-Cook constitutive relation and 


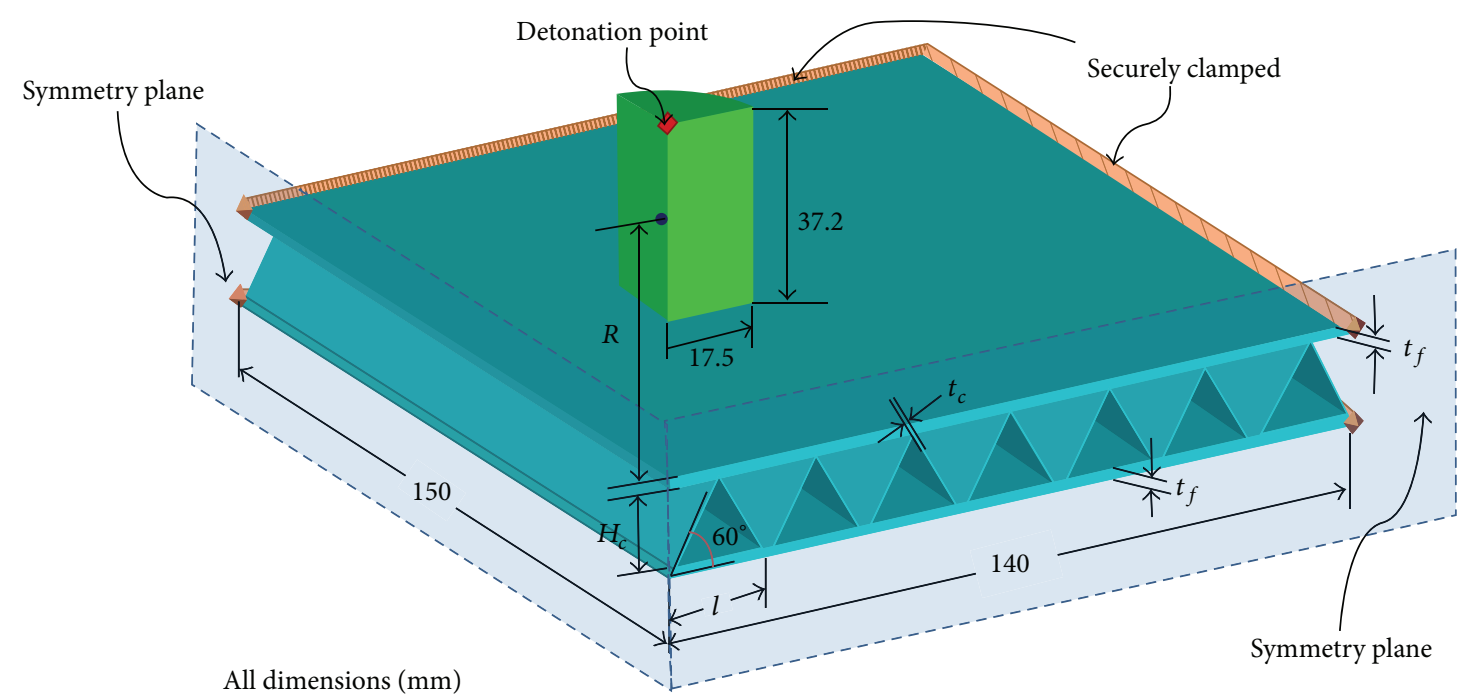

FIGURE 1: Geometric models of the one-quarter corrugated sandwich panel and the one-quarter cylindrical explosive.

Cockcroft-Latham failure criterion [17] to model the constitutive behavior of 6061-T6 aluminum alloy and adopted a fully coupled simulation approach based on discrete particlebased method to make a detailed investigation into FSI effects and fracture mechanisms of this complicated mechanical problem. The simulation results rationalized the local "streaks" phenomenon, which was arose from a local strong FSI effect, and explained how dimples formed at the corners of the test panels and well predicted panel failure at the clamped edges.

Despite a great deal of work on blast performance of sandwich panels, mostly about far-field blast, partly on the localized blast loading, there are a few reports about the dynamic response of corrugated core sandwich panels under near-field air blast loading. The aim of present study is to investigate the dynamic behavior of corrugated core sandwich panels subjected to highly intense near-field air blast loading and reveal the relationship between the structural performance metrics and geometry parameters by conducting numerical simulations.

\section{Geometry and Materials}

The examined sandwich panels consist of two equal thickness face sheets and corrugated core made of 304 stainless steel. The panels hold a given exposure area of $280 \mathrm{~mm} \times 300 \mathrm{~mm}$, and the web of corrugated core keeps a constant inclination angle of $60^{\circ}$. Meanwhile, the cylindrical TNT explosive is of a radius of $17.5 \mathrm{~mm}$ and a height of $37.2 \mathrm{~mm}$. The geometric model of corrugated sandwich panels is depicted in Figure 1. The geometric parameters of all sandwich panels considered in this study are listed in Table 1. The calculated equivalent solid plate thickness is listed in Table 2.

For the face sheets and core webs of sandwich panels made of the same material, the relative density $\bar{\rho}_{c}$ of core can be expressed as

$$
\bar{\rho}_{c}=\frac{t_{c}}{t_{c}+H_{c} \cos \alpha}
$$

where $t_{c}$ is the core web thickness, $H_{c}$ is the core thickness, and $\alpha$ is the inclination angle of core web.

The material used to fabricate the corrugated sandwich panels is annealed 304 stainless steel, which has high work hardening potential under explosion loading. Therefore, the Johnson-Cook plasticity formulation, which defines the flow stress as a function of equivalent plastic strain, strain rate, and temperature, is employed in all simulations. The dynamic flow stress is expressed by the following equation:

$$
\sigma_{y}=\left[A+B\left(\varepsilon_{p}^{\mathrm{eq}}\right)^{n}\right]\left[1+c \ln \left(\frac{\dot{\varepsilon}_{p}^{\mathrm{eq}}}{\dot{\varepsilon}_{0}}\right)\right]\left[1-\left(\frac{T-T_{r}}{T_{m}-T_{r}}\right)^{m}\right],
$$

where $\varepsilon_{p}^{\mathrm{eq}}$ and $\dot{\varepsilon}_{p}^{\mathrm{eq}}$ are equivalent plastic strain and equivalent plastic strain rate, respectively. $T$ is the material temperature, $T_{r}$ is the room temperature, and $T_{m}$ is the melting temperature of the material. $A, B, n, c, \dot{\varepsilon}_{0}$, and $m$ are Johnson-Cook parameters determined by fitting to the experimental curves. The material properties and the identified Johnson-Cook parameters [18] for the annealed 304 stainless steel are listed in Table 3. Although 304 stainless steel holds a desirable ductile performance to withstand the deformation produced by blast, the sandwich panel will fail under severely loaded test scenarios. Therefore, the failure criterion of 304 stainless steel based on the effective plastic strain is incorporated into numerical model. The rupture strain of material under impact is equal to 0.42 , according to Ahn et al's work [19].

Generally, the surrounding air and the product of TNT explosion are assumed to behave as ideal gas. The equation of state specified for ideal gas can be expressed as follows:

$$
p=(\gamma-1) \rho_{g} e_{0}, \quad \text { where } \gamma=\frac{C_{p}}{C_{v}}, \quad e_{0}=C_{v} T,
$$

where $\gamma$ is the adiabatic exponent, $\rho_{g}$ is the density of the gas, $e_{0}$ is the internal energy, $C_{p}$ and $C_{v}$ are the specific heat at constant pressure and volume respectively, and $T$ is the gas 


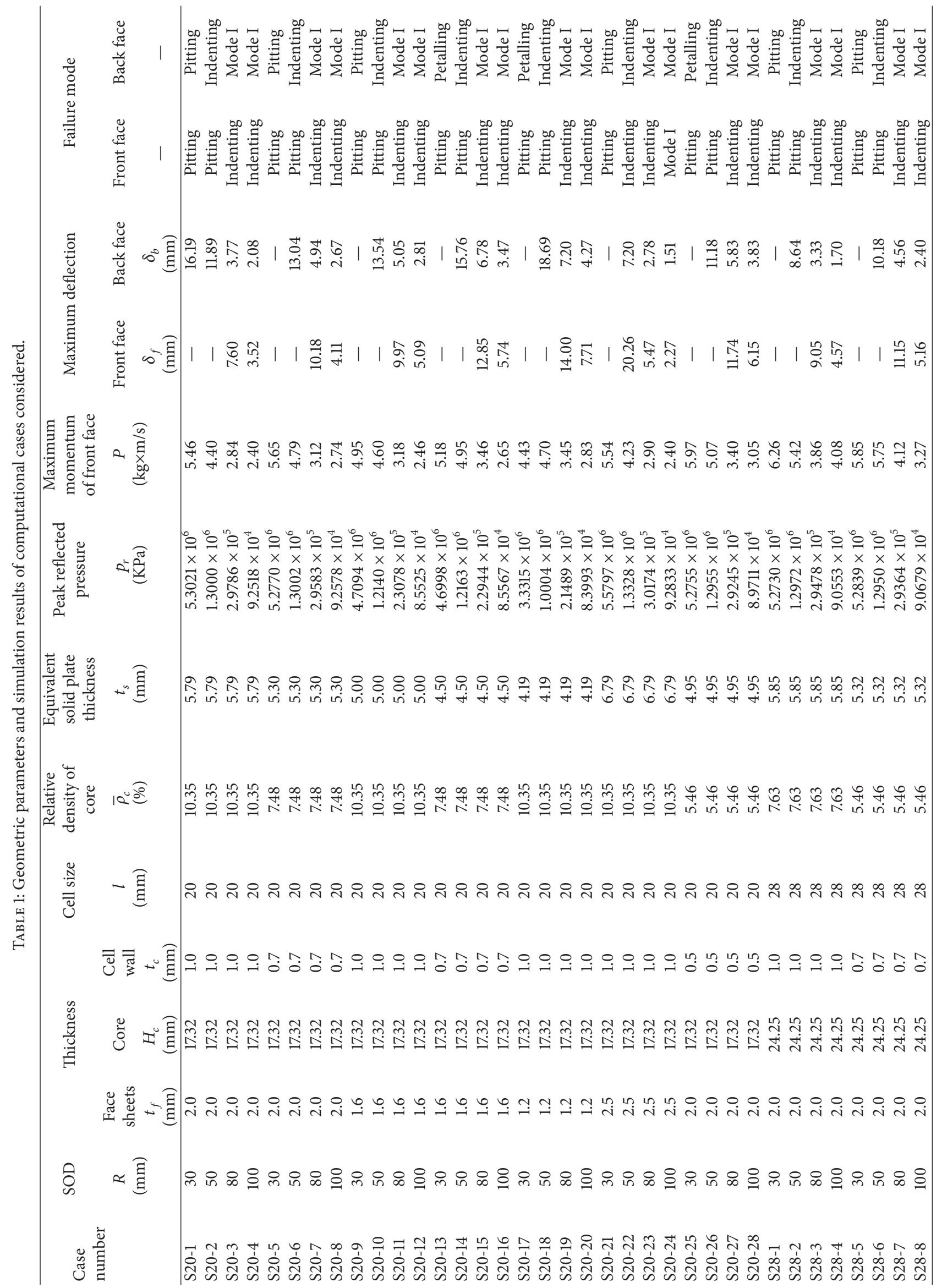




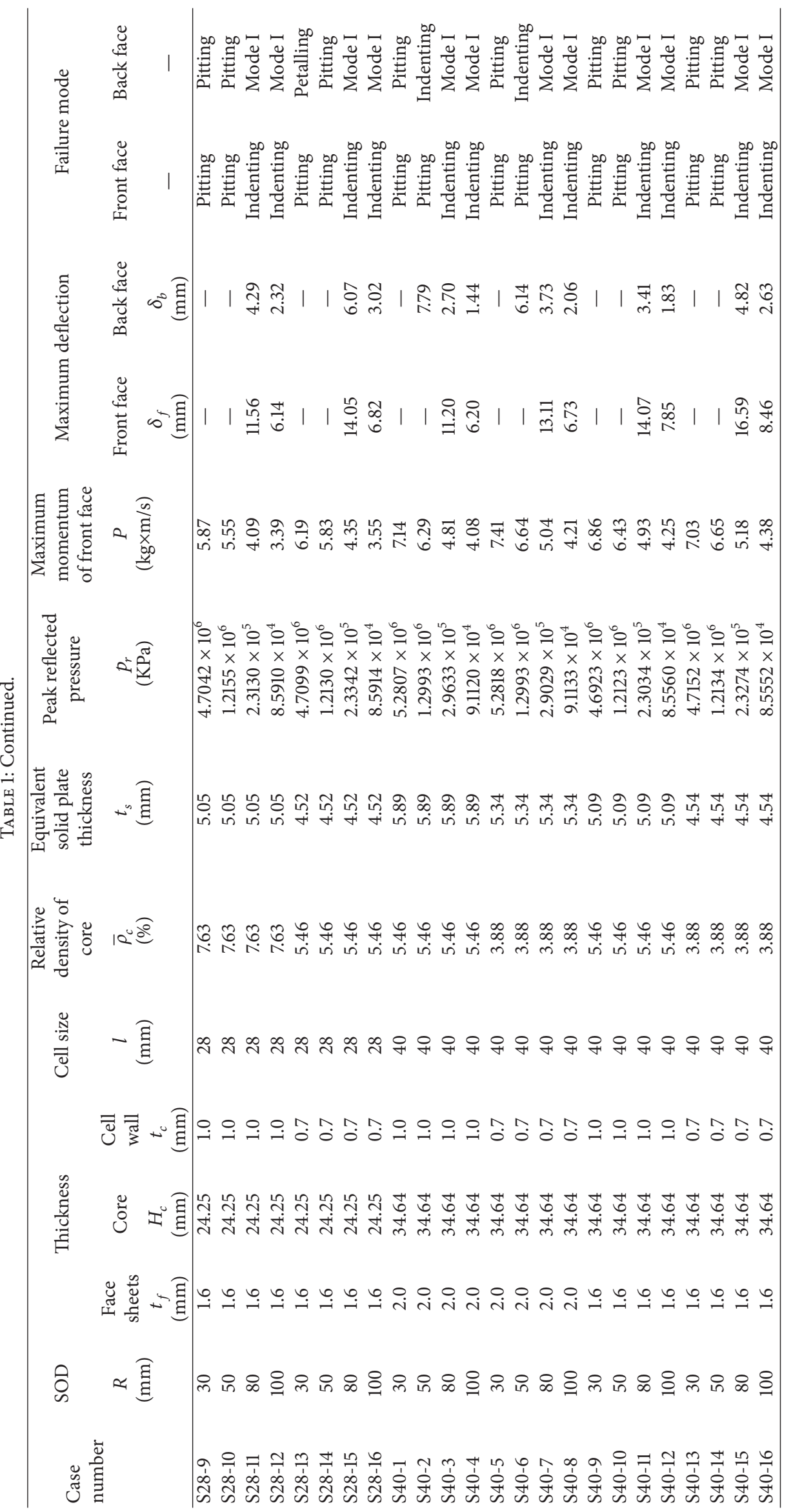


TABLE 2: Simulation results of equivalent solid plates.

\begin{tabular}{|c|c|c|c|c|c|c|}
\hline \multirow[t]{2}{*}{ Case number } & SOD & Thickness & $\begin{array}{c}\text { Peak reflected } \\
\text { pressure }\end{array}$ & Momentum & $\begin{array}{l}\text { Maximum } \\
\text { deflection }\end{array}$ & Failure mode \\
\hline & $\begin{array}{c}R \\
(\mathrm{~mm})\end{array}$ & $\begin{array}{c}t_{s} \\
(\mathrm{~mm})\end{array}$ & $\begin{array}{c}p_{r} \\
(\mathrm{KPa})\end{array}$ & $\begin{array}{c}P \\
(\mathrm{~kg} \times \mathrm{m} / \mathrm{s})\end{array}$ & $\begin{array}{c}\delta_{s} \\
(\mathrm{~mm})\end{array}$ & - \\
\hline SP-1 & 30 & 5.8 & $6.4101 \times 10^{6}$ & 10.34 & 30.34 & Mode I \\
\hline SP-2 & 50 & 5.8 & $1.4147 \times 10^{6}$ & 8.91 & 16.36 & Mode Ib \\
\hline SP-3 & 80 & 5.8 & $2.8021 \times 10^{5}$ & 7.26 & 7.75 & Mode Ib \\
\hline SP-4 & 100 & 5.8 & $9.2619 \times 10^{4}$ & 6.30 & 5.93 & Mode Ib \\
\hline SP-5 & 30 & 5.3 & $6.3730 \times 10^{6}$ & 10.35 & 33.57 & Mode I \\
\hline SP-6 & 50 & 5.3 & $1.4122 \times 10^{6}$ & 8.93 & 18.35 & Mode Ib \\
\hline SP-7 & 80 & 5.3 & $2.6578 \times 10^{5}$ & 7.30 & 8.60 & Mode Ib \\
\hline SP-8 & 100 & 5.3 & $9.2532 \times 10^{4}$ & 6.34 & 6.71 & Mode Ib \\
\hline SP-9 & 30 & 5.0 & $6.3287 \times 10^{6}$ & 10.35 & 35.73 & Mode I \\
\hline SP-10 & 50 & 5.0 & $1.4073 \times 10^{6}$ & 8.94 & 19.66 & Mode Ib \\
\hline SP-11 & 80 & 5.0 & $2.5159 \times 10^{5}$ & 7.32 & 9.28 & Mode Ib \\
\hline SP-12 & 100 & 5.0 & $9.2506 \times 10^{4}$ & 6.36 & 7.26 & Mode Ib \\
\hline SP-13 & 30 & 4.5 & $6.2330 \times 10^{6}$ & 10.36 & - & Petalling \\
\hline SP-14 & 50 & 4.5 & $1.3990 \times 10^{6}$ & 8.97 & 22.09 & Mode Ib \\
\hline SP-15 & 80 & 4.5 & $2.3856 \times 10^{5}$ & 7.37 & 10.57 & Mode Ib \\
\hline SP-16 & 100 & 4.5 & $9.2358 \times 10^{4}$ & 6.41 & 8.24 & Mode Ib \\
\hline SP-17 & 30 & 4.2 & $6.1957 \times 10^{6}$ & 10.37 & - & Petalling \\
\hline SP-18 & 50 & 4.2 & $1.3891 \times 10^{6}$ & 8.99 & 23.74 & Mode Ib \\
\hline SP-19 & 80 & 4.2 & $2.2945 \times 10^{5}$ & 7.40 & 11.41 & Mode Ib \\
\hline SP-20 & 100 & 4.2 & $9.2216 \times 10^{4}$ & 6.45 & 8.84 & Mode Ib \\
\hline SP-21 & 30 & 6.8 & $6.5412 \times 10^{6}$ & 10.32 & 25.24 & Mode I \\
\hline SP-22 & 50 & 6.8 & $1.4334 \times 10^{6}$ & 8.86 & 13.09 & Mode Ib \\
\hline SP-23 & 80 & 6.8 & $3.0678 \times 10^{5}$ & 7.19 & 6.14 & Mode Ib \\
\hline SP-24 & 100 & 6.8 & $9.3192 \times 10^{4}$ & 6.22 & 4.62 & Mode Ib \\
\hline
\end{tabular}

TABLE 3: Material properties and Johnson-Cook parameters for the annealed 304 stainless steel [18].

\begin{tabular}{lcccccccccccc}
\hline $\begin{array}{l}\rho \\
\left(\mathrm{kg} / \mathrm{m}^{3}\right)\end{array}$ & $\begin{array}{c}E \\
(\mathrm{GPa})\end{array}$ & $\nu$ & $\begin{array}{c}T_{m} \\
(\mathrm{~K})\end{array}$ & $\begin{array}{c}T_{r} \\
(\mathrm{~K})\end{array}$ & $\begin{array}{c}C \\
(\mathrm{~J} / \mathrm{kg} \mathrm{K})\end{array}$ & $\begin{array}{c}A \\
(\mathrm{MPa})\end{array}$ & $\begin{array}{c}B \\
(\mathrm{MPa})\end{array}$ & $n$ & $c$ & \multirow{2}{*}{$\dot{\varepsilon}_{0}$} & $m$ \\
\hline 7900 & 200 & 0.3 & 1673 & 293 & 440 & 310 & 1000 & 0.65 & 0.07 & 1.00 & 1.00 \\
\hline
\end{tabular}

temperature. The material properties of air adopted are from the ANSYS-AUTODYN material library, shown in Table 4.

Additionally, the Jones-Wilkins-Lee (JWL) EOS, which is currently in favor for hydrodynamic calculations of detonation product expansions, is used to model the behavior of TNT explosive. This equation defines the pressure of detonation product as a function of relative volume $\rho_{0} / \rho$ and internal energy per initial volume $E_{m 0}$, as shown in (4):

$$
\begin{aligned}
p= & A^{\prime}\left(1-\frac{\omega \rho_{e}}{R_{1} \rho_{0}}\right) e^{-R_{1}\left(\rho_{0} / \rho_{e}\right)} \\
& +B^{\prime}\left(1-\frac{\omega \rho_{e}}{R_{2} \rho_{0}}\right) e^{-R_{2}\left(\rho_{0} / \rho_{e}\right)}+\frac{\omega \rho_{e}}{\rho_{0}} E_{m 0},
\end{aligned}
$$

where $p$ is the blast pressure, $\rho_{e}$ and $\rho_{0}$ are the density of the explosive and explosive products respectively, and $E_{m 0}$ is specific internal energy of the explosive. The parameters
TABLE 4: Material properties of air [20].

\begin{tabular}{lcccc}
\hline $\begin{array}{l}\rho \\
\left(\mathrm{kg} / \mathrm{m}^{3}\right)\end{array}$ & $\begin{array}{c}T \\
(\mathrm{~K})\end{array}$ & $\begin{array}{c}C \\
(\mathrm{~J} / \mathrm{kg} \mathrm{K})\end{array}$ & $\gamma$ & $\begin{array}{c}e_{0} \\
(\mathrm{~kJ} / \mathrm{kg})\end{array}$ \\
\hline 1.225 & 288.2 & 717.6 & 1.4 & $2.068 \times 10^{5}$ \\
\hline
\end{tabular}

$A^{\prime}, B^{\prime}, R_{1}, R_{2}$, and $\omega$ are material constants which are related to the type of explosive. The material properties adopted for the TNT explosive are also from the ANSYS-AUTODYN material library, shown in Table 5.

\section{Numerical Model and Validation}

3.1. Numerical Model. The sandwich panels are peripherally clamped. Due to the symmetry of structure and loading condition, only one-quarter of the corrugated sandwich panel 
TABLE 5: Material properties of TNT explosive [20].

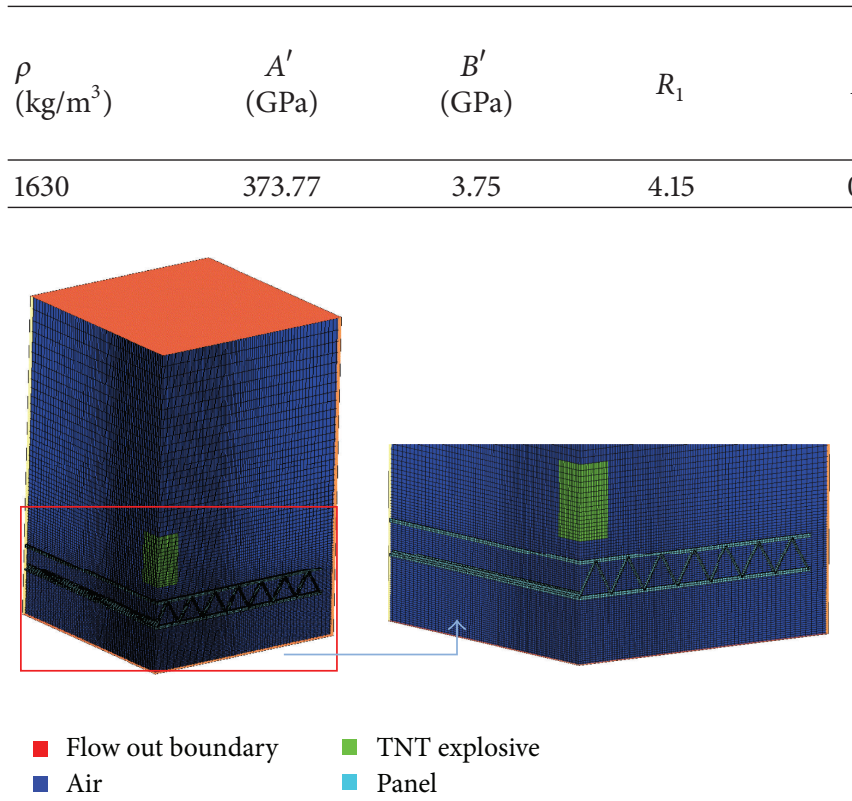

Figure 2: View of three-dimensional finite element model and high-resolution view of the field around sandwich panel. (For interpretation of the references to colour in this figure legend, the reader is referred to the web version of this paper.)

and cylindrical explosive are modeled in simulations. The three-dimensional numerical model used in this study is shown in Figure 2.

Both the face sheets and core are meshed using $1 \mathrm{~mm}$ Belytschko-Tsay shell element based on Mindlin plate theory [20]. Meanwhile, the surrounding air is modeled using EulerGodunov solver which is a second-order multimaterial Euler solver with the default SLIC (simplified line interface calculation) transport scheme in ANSYS-AUTODYN, and the cylindrical charge fills in the part of the surrounding air. Both the contact between the core cell wall and the face sheets due to the plastic buckling and the self-contact of the core wall due to cell wall folding are taken into account in simulations. In addition, the Eulerian meshes fully couple with the shell elements. During the process of coupling, the Euler cells intersected by the Lagrange interface define a stress profile for the Lagrange boundary vertices. In return, the Lagrange interface defines a geometric constraint to the flow of material in the Euler grid. The parameter named "cover fraction limit" is used to determine when a partially covered Euler cell is blended to a neighbor cell. The value of cover fraction limit is set to 0.5 . During the discrete process, the size of the smallest cell in the surrounding Euler grid should be at most one half of the artificial thickness of shell element to guarantee the FSI effect. In addition, the mesh of surrounding air is biased towards the field near to sandwich panels (shown in Figure 2). The mesh optimization has been executed to make a tradeoff between the results of computation and the computation efficiency.

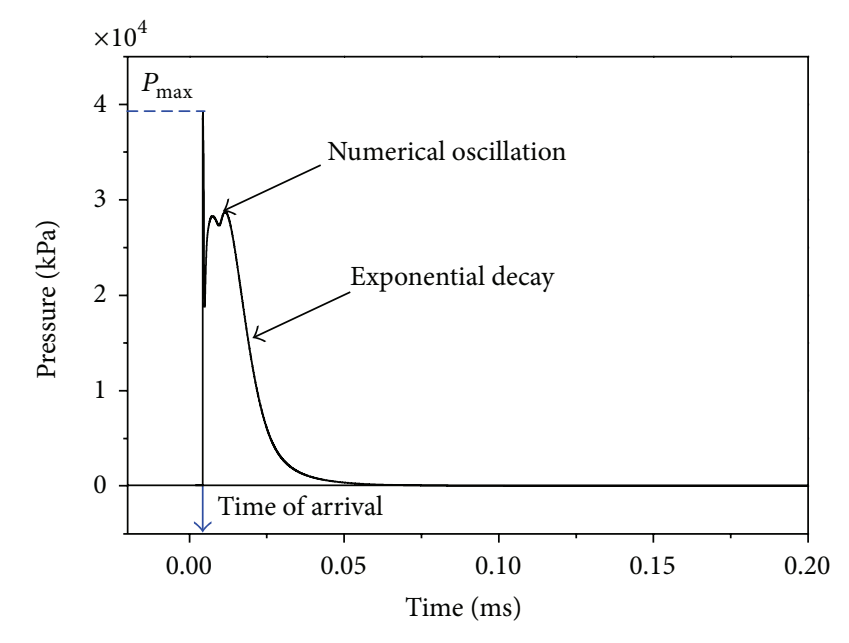

FIgURE 3: History of the air-blast induced pressure at the stand-off distance of $30 \mathrm{~mm}$.

\subsection{Validation}

3.2.1. Free Field Air Blast Pressure. The $2 \mathrm{D}$ axial symmetry model with a very fine Eulerian mesh is used to simulate the detonation and expanding process of a $55 \mathrm{~g}$ spherical explosive placed in an infinity atmosphere field. Figure 3 shows the pressure-time history of a gauge point positioned at a stand-off distance of $30 \mathrm{~mm}$. It is found that a slight numerical oscillation of pressure appeared after the pressure reaches the peak value and followed by exponential decay. The impulse carried by shock wave, as a key factor to determinate the deflection of blast loaded plates, can be calculated by the time integration of pressure. It is believed that the error due to numerical oscillation exerts a weak influence on the area under the pressure line.

A comparison is made between the simulation results and the predicting values of the fitting equation developed by Kinney and Graham [21] in terms of the peak pressure of stand-off distances with range from $30 \mathrm{~mm}$ to $200 \mathrm{~mm}$, as shown in Figure 4. It is clear that the numerical results are very close to the predicting values.

3.2.2. Structure/Blast Interaction. A series of experiments of clamped mild steel quadrangular plates to localized air blast loading were conducted by Jacob et al. [22]. The test plates were made of mild steel and cut from the shelf cold rolled plates. The blast loading was generated by the detonation of a plastic explosive with circular dish shape. The plastic explosive was placed at the center of a polystyrene foam pad with thickness of $12 \mathrm{~mm}$ and detonated by a short stub detonator with mass of $1 \mathrm{~g}$. The mass of charge is in the range of $3.5-4.5 \mathrm{~g}$. 


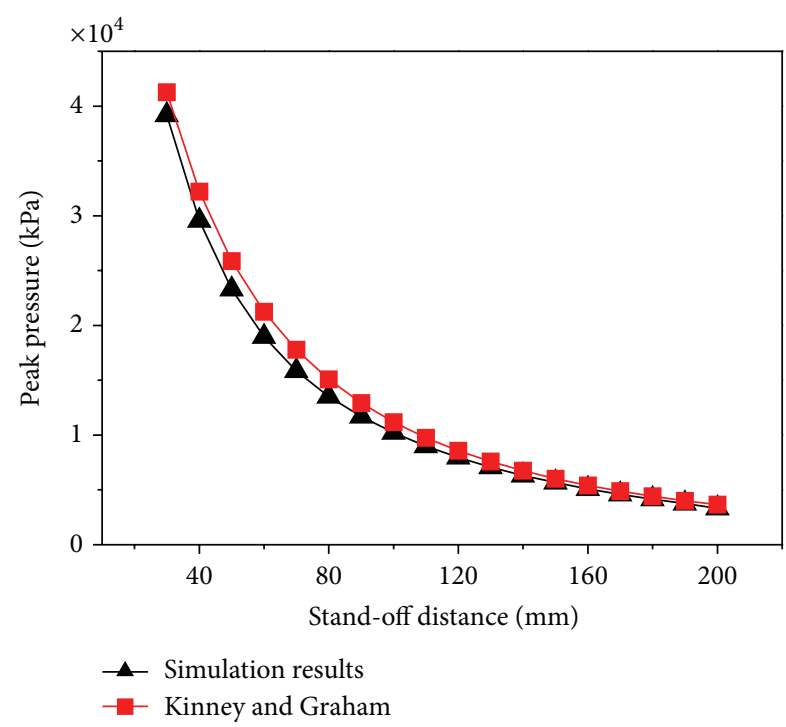

FIGURE 4: Peak pressure versus stand-off distance for simulation results and the fitting equation developed by Kinney and Graham [21].

Therefore, the damage power of detonator should be taken into account in simulations. But the outline of the detonator was not given. The charge height was changed to ensure that the weight of the charge modeled in simulation was equal to the summation of the weight of detonator and the charge used in experiments. However, this would result in an overprediction of the damage power of detonator, as a result of that the stand-off distance between the plate and detonator is smaller.

To intuitively validate the numerical approach used in this study, five experimental cases possessing detailed postmortem profiles are selected to simulate the dynamic response process using ANSYS-AUTODYN. Exposed area of those impacted square plates is $190 \mathrm{~mm} \times 129 \mathrm{~mm}$, and the thickness of the plates is $1.6 \mathrm{~mm}$. The material coefficients used to model the dynamic mechanical behavior of impacted plates are given by Jacob et al. [22]. The one-quarter finite element models of a test plate and air field are shown in Figure 5. The finite element model of plate consists of 5,000 quadrilateral elements, while the finite element model of air field consists of 1,000,000 hexahedral elements.

Figure 6 shows the cross-sectional profiles of experiments and numerical simulations in each case. It is observed that partial tearing appeared in the central area both in the experiment and simulation for the test case of N01100122 and the predicted profiles are closely similar to experimental results. The comparison of predicted center point deflections and measured values is presented in Table 6 . The simulation results fit well with the experimental results, except small overestimation observed in simulations. The main reason is that the damage power of detonator is overpredicted. It is concluded that the numerical method adopted in the simulations is accurate enough, which is expected to be applied in the dynamic analysis of complex constructions to near-field air blast loading, such as sandwich panels.

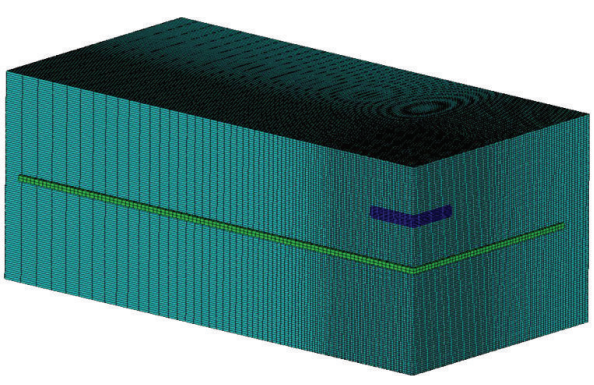

FIgURE 5: One-quarter finite element models of quadrangular plate and air field.

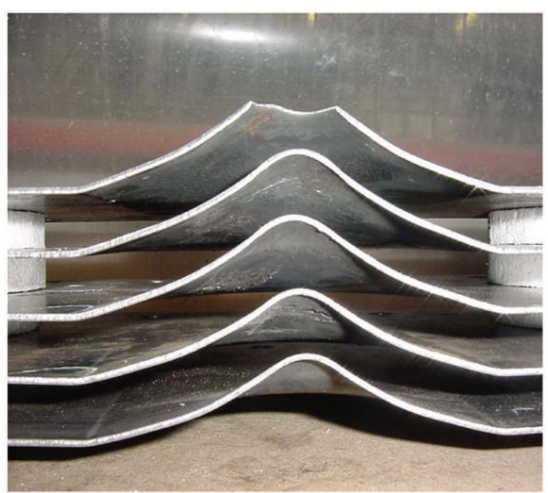

(a)
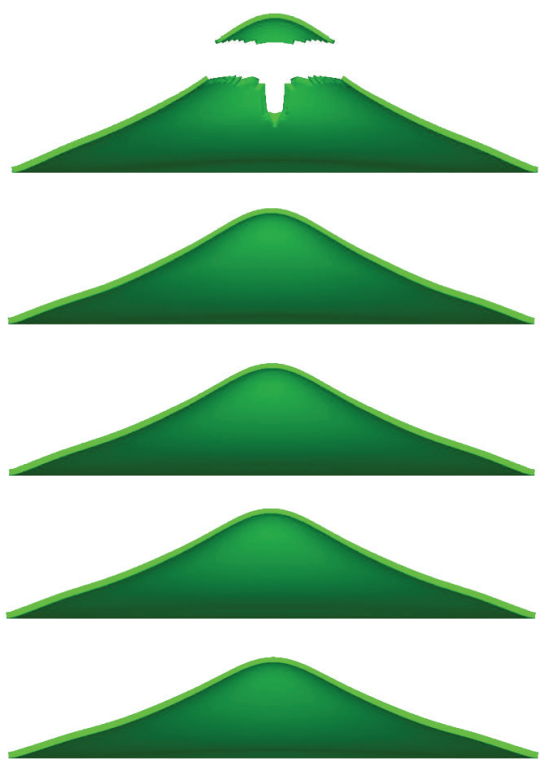

(b)

FIGURE 6: Comparison of cross sectional profiles of (a) experiments [22] and (b) proposed simulations. The test numbers from bottom to top are N021100124, N01100123, N22100145, N01100121, and N01100122.

\section{Numerical Simulation Results}

Using sandwich panel for impact mitigation, the protecting construction designers generally assess the performance of sandwich panel from following aspects: impulse on front 
TABLE 6: Experimental and numerical results for selected cases.

\begin{tabular}{lcccc}
\hline Test number & $\begin{array}{c}\text { Mass of charge } \\
(\mathrm{g})\end{array}$ & $\begin{array}{c}\text { Experimental displacement } \\
(\mathrm{mm})\end{array}$ & $\begin{array}{c}\text { Numerical displacement } \\
(\mathrm{mm})\end{array}$ & $\begin{array}{c}\text { Relative error } \\
(\%)\end{array}$ \\
\hline N02100124 & 3.5 & 20.4 & 22.8 & 11.8 \\
N01100123 & 3.8 & 21.4 & 25.2 & 17.8 \\
N01100121 & 4.0 & 23.7 & 26.7 & 12.7 \\
N22100145 & 3.9 & 23.4 & 25.9 & 10.7 \\
N01100122 & 4.5 & Tearing & Tearing & - \\
\hline
\end{tabular}

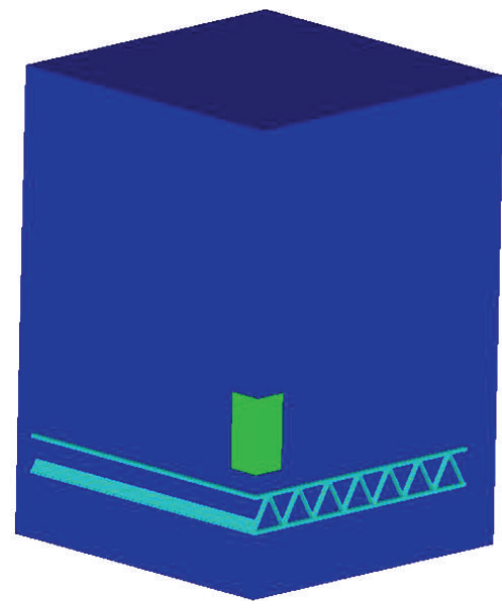

(a) $t=0 \mu \mathrm{s}$

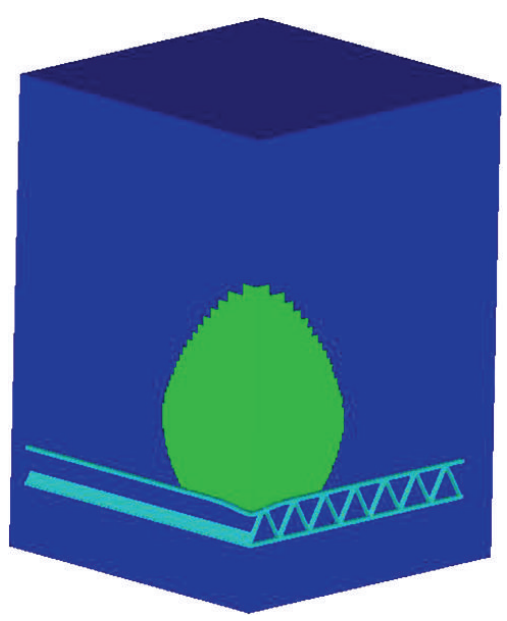

(d) $t=12.1 \mu \mathrm{s}$

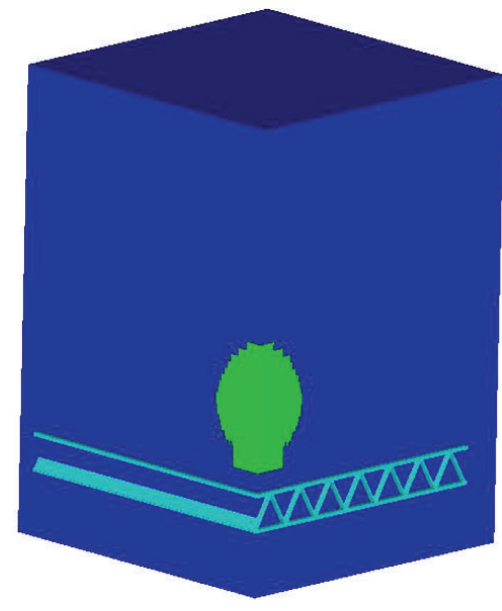

(b) $t=4.3 \mu \mathrm{s}$

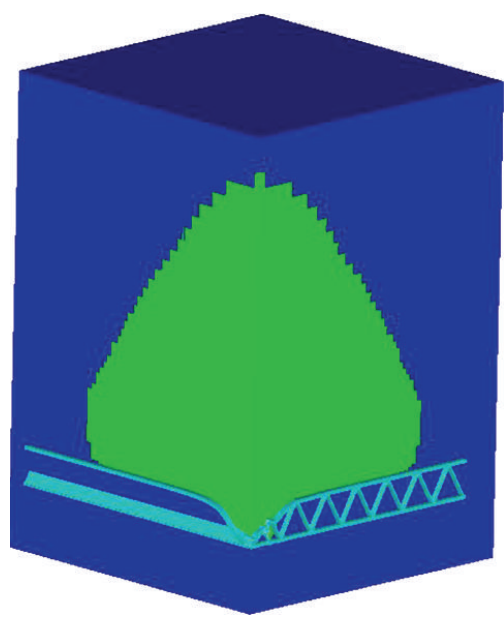

(e) $t=27.0 \mu \mathrm{s}$

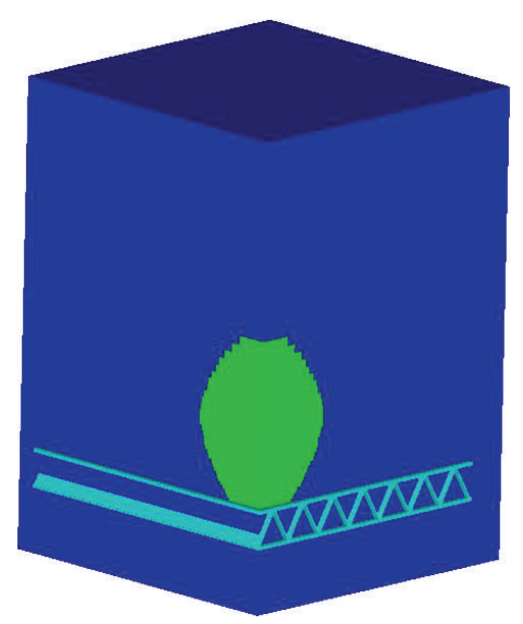

(c) $t=7.0 \mu \mathrm{s}$

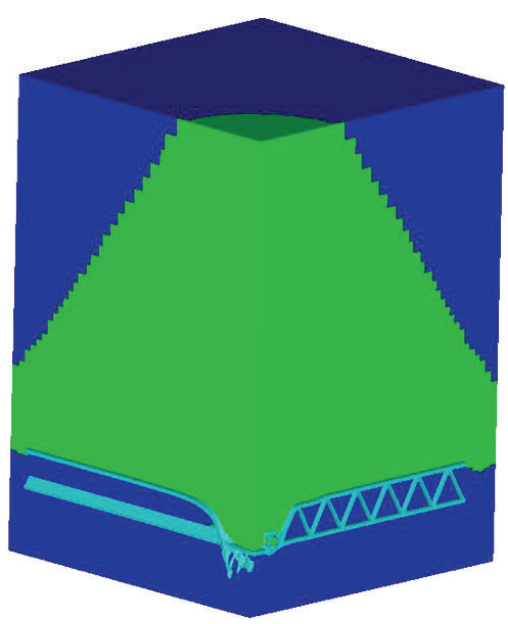

(f) $t=45.4 \mu \mathrm{s}$

FIGURE 7: AUTODYN screenshots showing the transient response of the detonation products and the sandwich panel (case number S20-1).

plate, permanent deflections, history of pressure near or on the FSI surface, and the deformation/failure patterns.

Figure 7 shows typical results of the fully coupled calculation revealing the interaction between the explosive gas products and the sandwich panel (Case number S201). Figure 7(a) gives the initial state of the explosive and sandwich panel at $t=0$. The cylindrical explosive is instantly ignited at this moment by the detonator placed at the center point of the top face of charge. At $t=4.3 \mu \mathrm{s}$, the explosive gas products abruptly expand outward to compress the surrounding air and then begin to interact with the front surface of sandwich panel at $t=7.0 \mu \mathrm{s}$. Once interacting, the sandwich panel acts as flow boundary for the expanded explosive products, reversely, which exert pressure load on structure. At the initial stage of fluid-structure interaction, the sandwich panel nearly keeps undeformed for two reasons: (1) the imparted momentum to sandwich panel is not enough large and (2) the structural response behaves a degree of time hysteresis. A dent failure is firstly formed at the central area of sandwich front face at $t=12.1 \mu \mathrm{s}$, which has been also found by Zhu et al. [23]. After that, the deformation extends outwards and downwards with the transferring of impulse. 


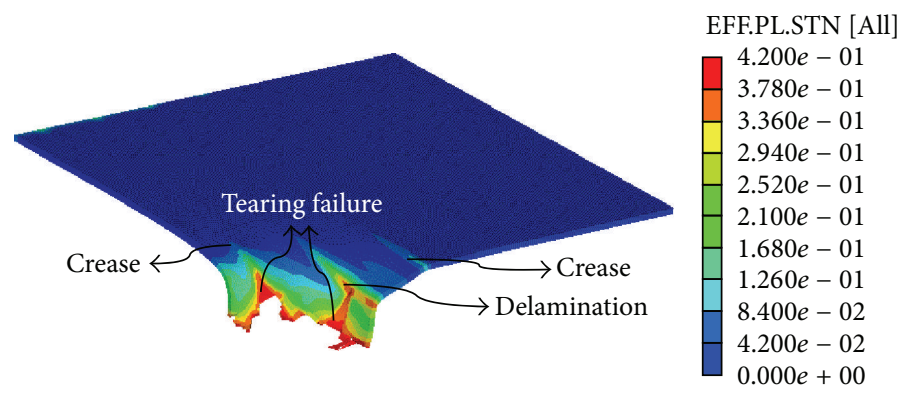

(a) Front face

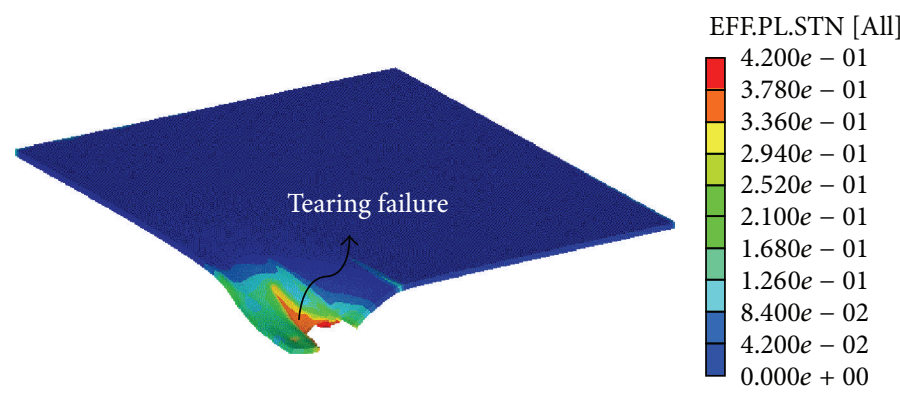

(b) Back face

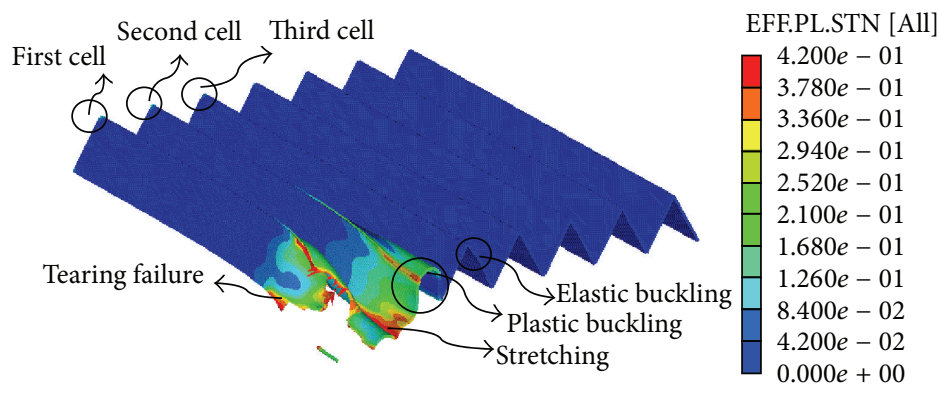

(c) Corrugated core

FIGURE 8: Deformation and failure patterns of a sandwich panel (case number S20-1). (For interpretation of the references to colour in this figure legend, the reader is referred to the web version of this paper.)

The front face deforms continually to slap into the back face at $t=27.0 \mu \mathrm{s}$. In this process, the middle core webs provide the resistance force to the front face and begin to crush. Due to the large stretching and bending deformation, the front face fails at the joint between the front face sheet and middle core web and then the explosive products permeate into the inner space of cell. As the simulation proceeding, the face sheets and the core continue to deform under their inertia, shown in Figure 7(f), and the contact detected between them does its work in subsequent process till the contact force reduces to 0 .

After the slight oscillation of the sandwich panel due to the occurrence of spring back effect, all kinetic energy of the structure is dissipated by the plastic bending and stretching of face sheets and the crushing of corrugated core. The final material status and deformation/failure patterns of a panel are shown in Figure 8. Overall, most part of the sandwich panel sinks into plastic status. In the central portion of front and back face sheets, the pitting failure which is characterized by a localized pit and fracture on the surface occurs, and significant tearing failure is observed on both the front and back faces along the middle ridge of corrugated core, shown in Figures 8(a) and 8(b). Careful examination shows that some creases are formed on front face along those ridges of corrugated core owing to the localized supporting force of core web, and delamination failure between the front face and core also occurs, as indicated in Figure 8(a). Under the loading force of pressured explosive products, the front face gains considerable momentum away from blast location and undergoes extremely large stretching deformation which leads central part material to failing, and the eroding effect based on geometric strain is applied to those excessively distorted elements. Figure 8(c) illustrates the failure mode of a corrugate core under near-field air blast loading. The crushing strains of corrugated core webs in the central portion are greatest enough to fail, because of the greatest applied pressure associated with the charge location. The webs of the second (sorted from center to outskirts) cell undergo remarkable plastic buckling deformation; meanwhile, the webs of the third cell undergo elastic buckling 


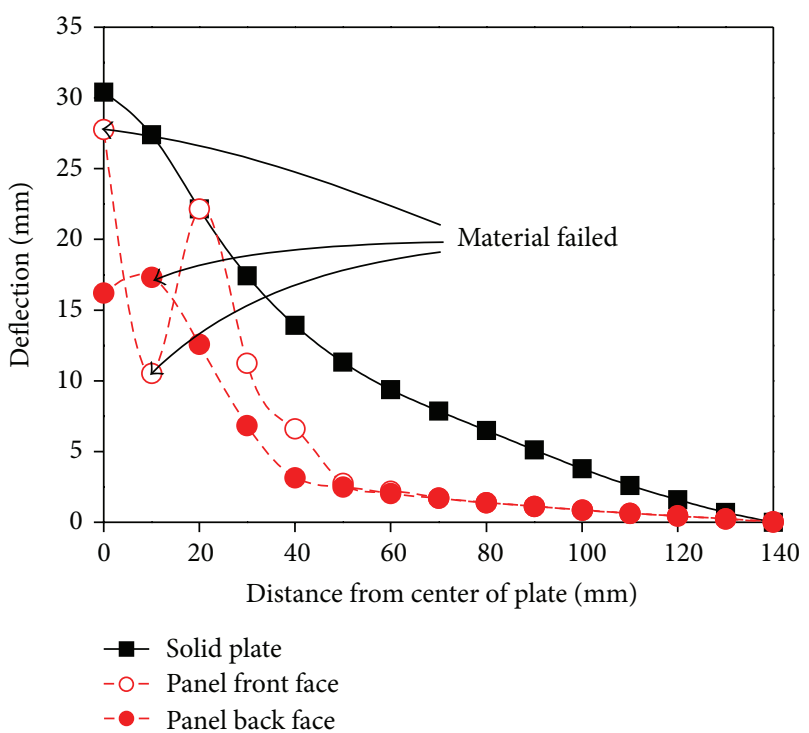

(a)

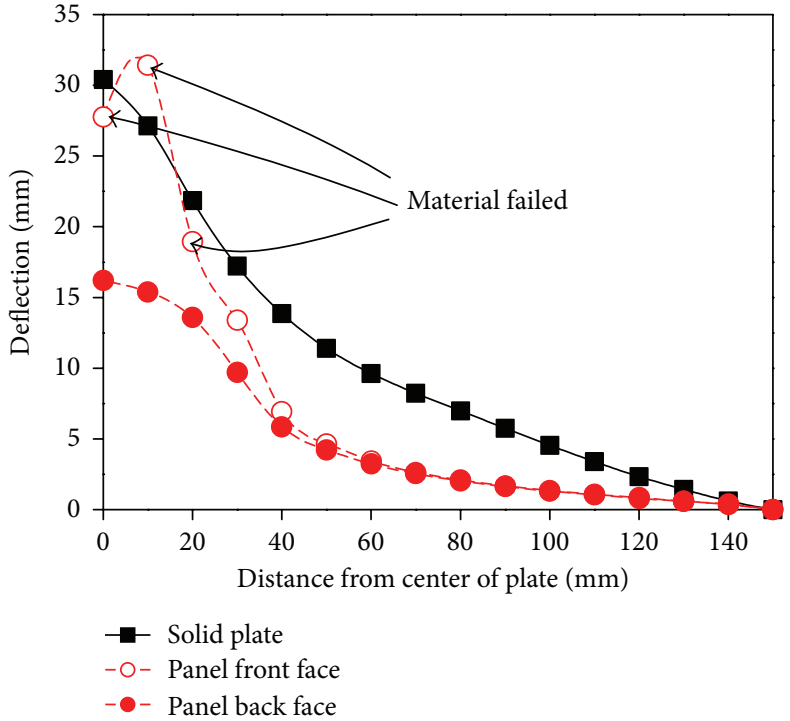

(b)

FIGURE 9: Sandwich panel (case number S20-1) and solid plate (case number SP-1) sectioned profiles predicted along (a) the direction perpendicular to corrugations and (b) the direction parallel to corrugations.

deformation, whereas the others nearly remain undeformed. The failure modes of the panels and solid plates tested herein are identified and listed in Tables 1 and 2, respectively.

The predicted sectioned half profiles along the directions parallel to corrugations and perpendicular to corrugations are plotted in Figure 9 for the sandwich panel and equivalent weight monolithic plate under the same air blast loading. The midpoint of back face of sandwich panel only undergoes half deflection of solid plate midpoint. The difference value between the front face and back face deflections reveals that the core crushing effect is outstanding in the center area but vanishes in the outskirts field under near-field air blast. A significant local bending deformation superimposes on the global bending deformation of front face along the direction perpendicular to corrugations in the center field. The global inelastic deformation plays a dominative role in the exterior zone of front face. The local bending deformation is not clear on the back face and front face (along the direction parallel to corrugations). It is also found that the material of center field of front face sheet fails under this high-intensity loading, and the tearing failure occurs on the back face between the first cell core webs (Figure 8(b)).

In order to better understand FSI effect, the distributions of pressure are investigated both temporally and spatially. Several pressure gauges are intentionally placed in air field above the shock impacted plates along the axis of cylindrical charge. The exact locations of those pressure gauges are shown in Figure 10. The location of Gauge 1 is firstly occupied by the undeformed test plate at initial state, and Gauge 2 is placed near the FSI surface to measure the pressure of the reflected shock wave. The distances between the adjacent gauges are equal to $2 \mathrm{~mm}$. The pressure-time histories of five pressure gauges for a sandwich panel (case number S20-1) and an equivalent weight monolithic plate (case number SP-1)

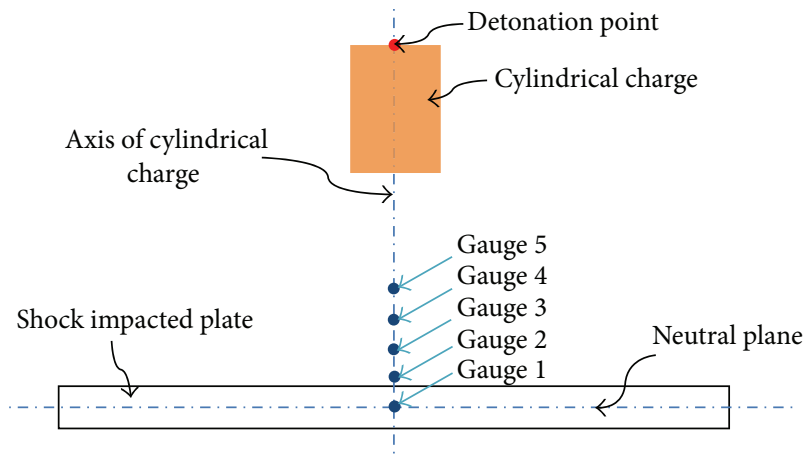

FIGURE 10: Locations of pressure gauges placed.

under the same explosion loading are shown in Figure 11. The incident wave travels forward via Gauge 5 firstly. It is observed from Gauges 2-5 that the pressure jump phenomenon for the incident wave is not evident. But this phenomenon ordinarily exists in far-field explosion. This is due to the fact that the impacted plate restricts the expansion of explosive products. Those air particles close to FSI surface, like those around Gauges $2-5$, have been rapidly compressed due to the expansion of explosive production, leading to increase of pressure. Therefore, at the initial phase, the increase of pressure of the locations Gauges $2-5$ is induced not only by the highpressure incident shock front but also by the highly nonlinear compression of air medium. The pressure of reflected wave deserves more attention because it is the effective loading on structure. Using a solid plate (case number SP-1) as a benchmark, the sandwich panel (case number S20-1) gives a decrease of peak reflected pressure by $17.3 \%$ as a result of the beneficial FSI effect. It is noticeable that the pressure-time 


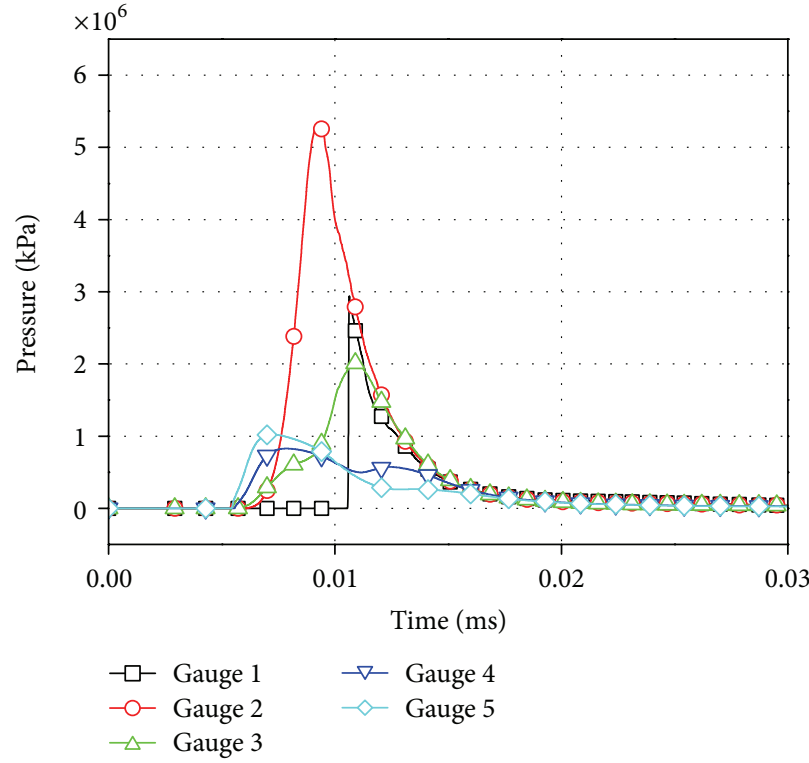

(a)

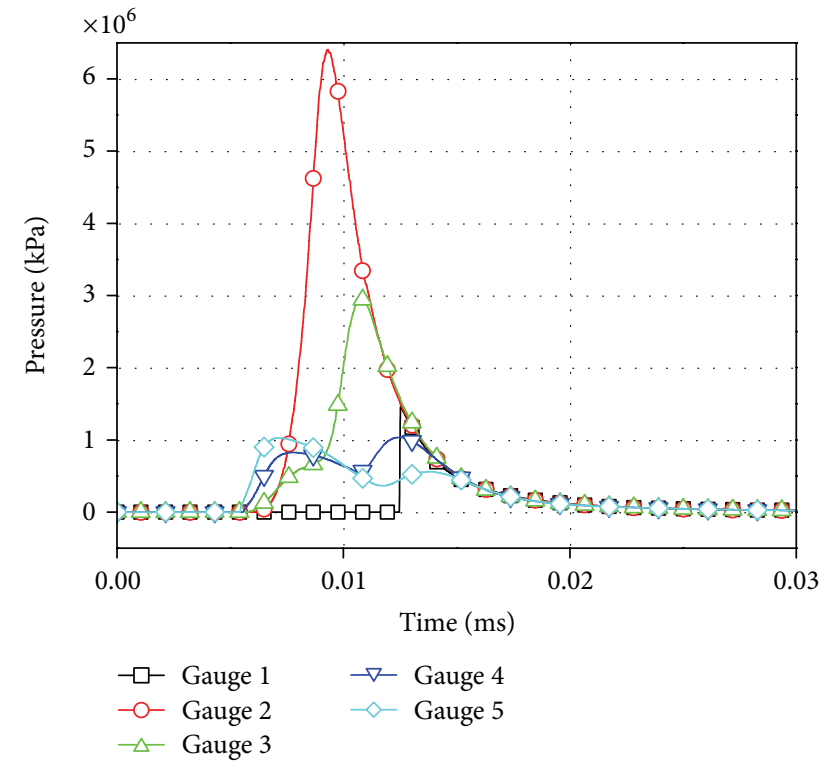

(b)

FIGURE 11: Pressure-time history of gauges placed in air field along the axis of cylindrical charge for the test plates. (a) Sandwich panel (case number S20-1) and (b) solid plate (case number SP-1).

curves of Gauges 3-5 hold a double-humped feature. Gauge 3 is characterized by a high hump for reflected shock and a low hump for incident shock. As the decay of the reflected shock wave, the characteristics of Gauges 4-5 are just reverse to that of Gauge 3. And the pressure of Gauge 1 increases abruptly as the explosive products flow into the field occupied by the test plates initially.

Figure 12 shows that the peak reflected pressure decays very fast from center to outside. It conforms that sandwich panel construction with light face sheet can reduce the reflected pressure. However, this benefit of the sandwich panel construction over an equivalent weight solid plate is evident only in the center field of plate under near-field air blast loading. It is shown that the locality characteristic inferred from the deformation pattern is not exhibited in pressure field.

\section{Discussions}

The performance of corrugated core sandwich panels under explosion loading is closely related to the geometric parameters of panels. In this research, a parametric study is conducted to reveal the relationship between the key characteristics (deformation/failure, impulse transmitted, and peak pressure near FSI surface) of structural response and several specific geometry parameters (stand-off distance, face sheet thickness, cell size, and core web thickness, relative density of core). The results of parametric study are presented in this section.

5.1. Effect of Stand-off Distance. To investigate the effect of stand-off distance on the deformation/failure pattern and the reflected pressure, all panel configurations and solid plates considered here are subjected to the air blast loading created by the detonation of the TNT charge with a given mass but at stand-off distances of $30 \mathrm{~mm}, 50 \mathrm{~mm}, 80 \mathrm{~mm}$, and $100 \mathrm{~mm}$, respectively.

Figure 13 shows the final deformation/failure patterns of the sandwich panels with the same face sheet thickness $\left(t_{f}=\right.$ $2.0 \mathrm{~mm})$ and core web thickness $\left(t_{c}=1.0 \mathrm{~mm}\right)$ but different cell sizes $(l=20,28$, and $40 \mathrm{~mm}$, resp.) and equivalent weight solid plates under different stand-off distances. It is found that the failure modes of front face turn from the pitting failure to indenting failure with the increase of stand-off distance and that those of back face turn from the pitting failure and petalling failure to the global dome failure (Mode I failure). Meanwhile, the failure modes of equivalent solid plates turn from the global dome failure attached by an inner dome to just the global dome failure. Additionally, the failure area of structures is larger at lower stand-off distance. As expected, the center deflections of sandwich front face, back face, and solid plates decrease with the increase of stand-off distance, as shown in Figure 14. The plot illustrates that the benefits of the sandwich panel construction over a solid plate to withstand blast loads are clearly evident with smaller back plate deflections compared with the equivalent weight solid plates subjected to the same loads. However, the explosion loading for a given charge mass at lower stand-off distance exhibits high intensity and spatial localization. And the back faces of some sandwich panel configurations are likely to fail under this loading. Therefore, the benefits of sandwich panel will vanish in this case. Figure 13 shows that tearing damage occurs on the back face of sandwich panels with cell sizes of $28 \mathrm{~mm}$ and $40 \mathrm{~mm}$ subjected to the explosion loading at the standoff distance of $30 \mathrm{~mm}$. Careful examination shows that some streaks are formed on front face between the core webs owing to the effect of a locally strong FSI, shown in Figure 13. 


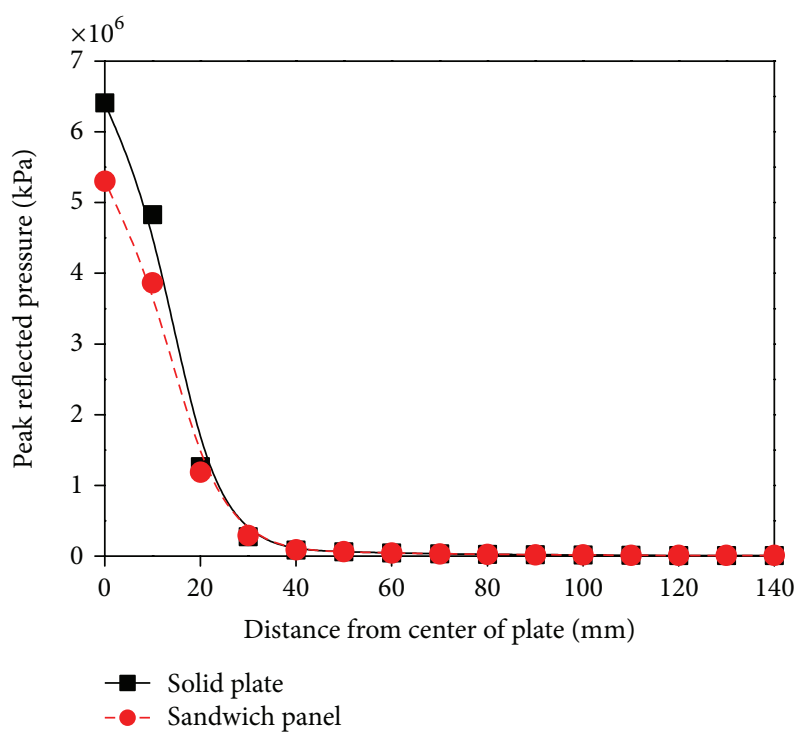

(a)

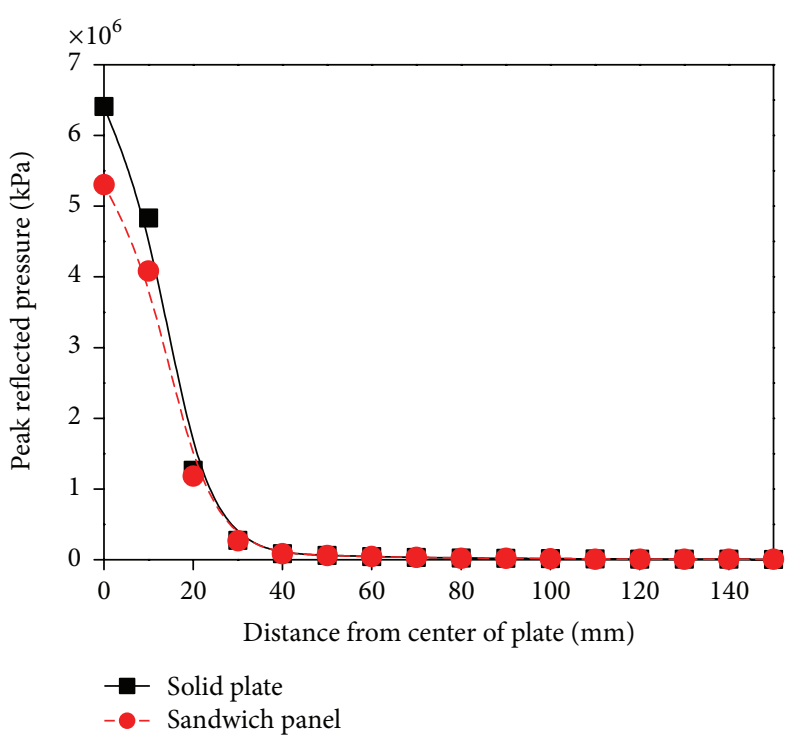

(b)

FIGURE 12: Spatial distributions of peak reflected pressure near the FSI surface along (a) the direction perpendicular to corrugations and (b) the direction parallel to corrugations.
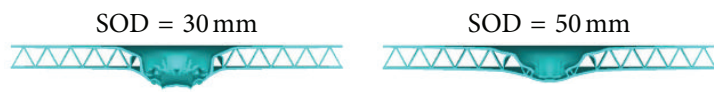

Increasing stand-off distance

(a)
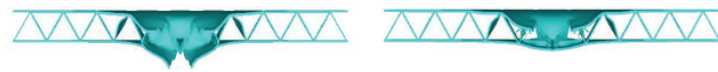

Increasing stand-off distance

(b)
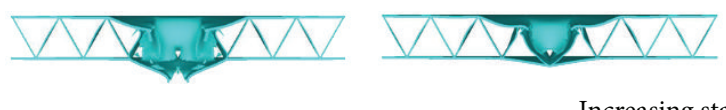

Increasing stand-off distance

(c)
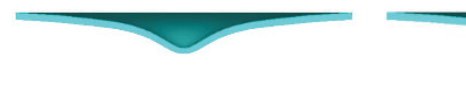

Increasing stand-off distance

(d)

Figure 13: Cross-sectional view of the deformation/failure modes of sandwich panels and equivalent solid plates under different stand-off distances. (a) $t_{f}=2.0 \mathrm{~mm}, t_{c}=1.0 \mathrm{~mm}$, and $l=20 \mathrm{~mm}$; (b) $t_{f}=2.0 \mathrm{~mm}, t_{c}=1.0 \mathrm{~mm}$, and $l=28 \mathrm{~mm}$; (c) $t_{f}=2.0 \mathrm{~mm}, t_{c}=1.0 \mathrm{~mm}$, and $l=40 \mathrm{~mm} ;(\mathrm{d}) t_{s}=5.8 \mathrm{~mm}$.

The peak reflected pressure of the FSI surface is an important index for quantitatively analyzing the benefits of the FSI effect. Figure 15 shows the peak reflected pressure of the air particle placed at the center point of the sandwich panel front faces and the solid plates. Those sandwich panels with the same core configuration $\left(t_{c}=1.0 \mathrm{~mm}, l=20 \mathrm{~mm}\right)$ but different face sheet thicknesses $\left(t_{f}=1.2 \mathrm{~mm}, 1.6 \mathrm{~mm}\right.$, $2.0 \mathrm{~mm}$ and $2.5 \mathrm{~mm}$ ) are chosen to contrast with equivalent solid plates. It is found that the sandwich panel with a lower peak reflected pressure performs better than the equivalent weight solid plate as a result of the lower inertia of sandwich panel front face. This benefit of sandwich construction is more remarkable for air blast loading at lower stand-off distance, and the influence rule of stand-off distance on peak reflected pressure is the same for panels with different face sheet thicknesses. Using the equivalent solid plates as a benchmark, these four sandwich panels with face sheet thicknesses of $1.2 \mathrm{~mm}, 1.6 \mathrm{~mm}, 2.0 \mathrm{~mm}$, and $2.5 \mathrm{~mm}$ lead to 


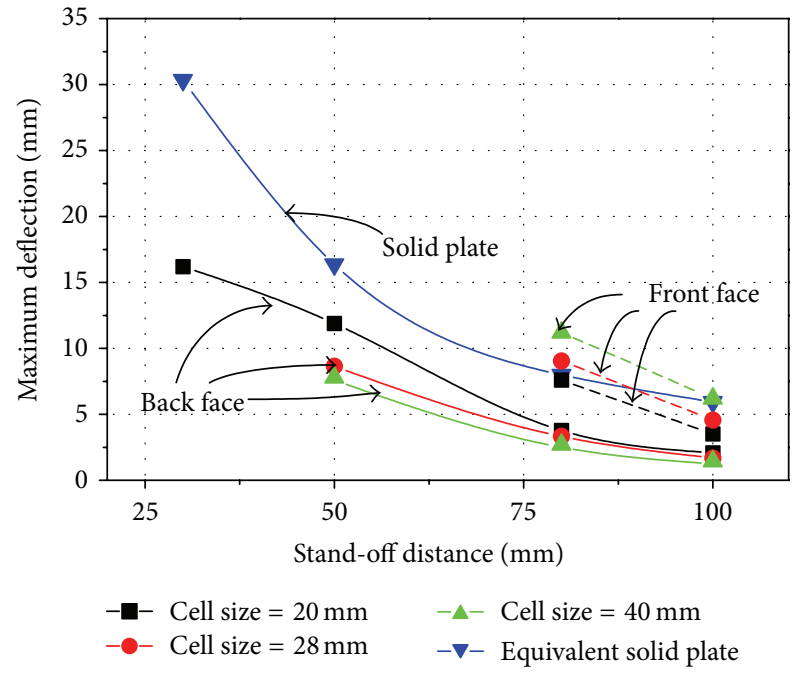

FIGURE 14: Comparison of the center deflection of the sandwich panel front face, back face, and equivalent weight solid plate versus the stand-off distance. $t_{f}=2.0 \mathrm{~mm} ; t_{c}=1.0 \mathrm{~mm} ; t_{s}=5.8 \mathrm{~mm}$.

a decrease in the peak reflected pressures by $46.23 \%, 25.59 \%$, $17.29 \%$, and $14.7 \%$ at the stand-off distance of $30 \mathrm{~mm} ; 27.98 \%$, $13.74 \%, 8.11 \%$, and $7.02 \%$ at the stand-off distance of $50 \mathrm{~mm}$; $6.35 \%, 8.27 \%, 0.71 \%$, and $1.64 \%$ at the stand-off distance of $80 \mathrm{~mm}$; and $8.92 \%, 7.55 \%, 0.11 \%$, and $0.39 \%$ at the stand-off distance of $100 \mathrm{~mm}$, respectively.

5.2. Effect of Face Sheet Thickness. The thickness of front face sheet is critical to the FSI effect. Therefore, the investigation of the effect of face sheet thickness is necessary to reveal some inherent laws to guide the design of corrugated core sandwich panel.

As indicated in Figure 15, the thickness of front face has a significant influence on the peak reflected pressure. If the thickest front face $(2.5 \mathrm{~mm})$ is adopted as a benchmark, the other front faces $(1.2 \mathrm{~mm}, 1.6 \mathrm{~mm}$, and $2.0 \mathrm{~mm})$ give a decrease of peak reflected pressure by $40.29 \%, 15.6 \%$, and $4.98 \%$ at stand-off distance of $30 \mathrm{~mm} ; 24.94 \%, 8.91 \%$, and $2.46 \%$ at stand-off distance of $50 \mathrm{~mm} ; 28.78 \%, 23.52 \%$, and $12.9 \%$ at stand-off distance of $80 \mathrm{~mm}$; and $9.52 \%, 7.87 \%$, and $0.34 \%$ at stand-off distance of $100 \mathrm{~mm}$, respectively. The benefit of FSI effect for sandwich construction is enhanced greatly as the reduction of face sheet thickness. Moreover, this effect of face sheet thickness is more outstanding under nearfield explosion condition.

To investigate the effect of face sheet thickness on the center deflection of front face and back face, the results of the sandwich panels with the same core configuration $\left(t_{c}=\right.$ $1.0 \mathrm{~mm}, l=20 \mathrm{~mm})$ and varied face sheet thicknesses $\left(t_{f}=\right.$ $1.2 \mathrm{~mm}, 1.6 \mathrm{~mm}, 2.0 \mathrm{~mm}$, and $2.5 \mathrm{~mm}$ ) are shown in Figure 16 . With the increase of the face sheet thickness, the deflections of midpoint reduce, especially under the near-field explosion loading, but it is an important issue for a designer to deal with the confliction properly between the stiffness and weight.
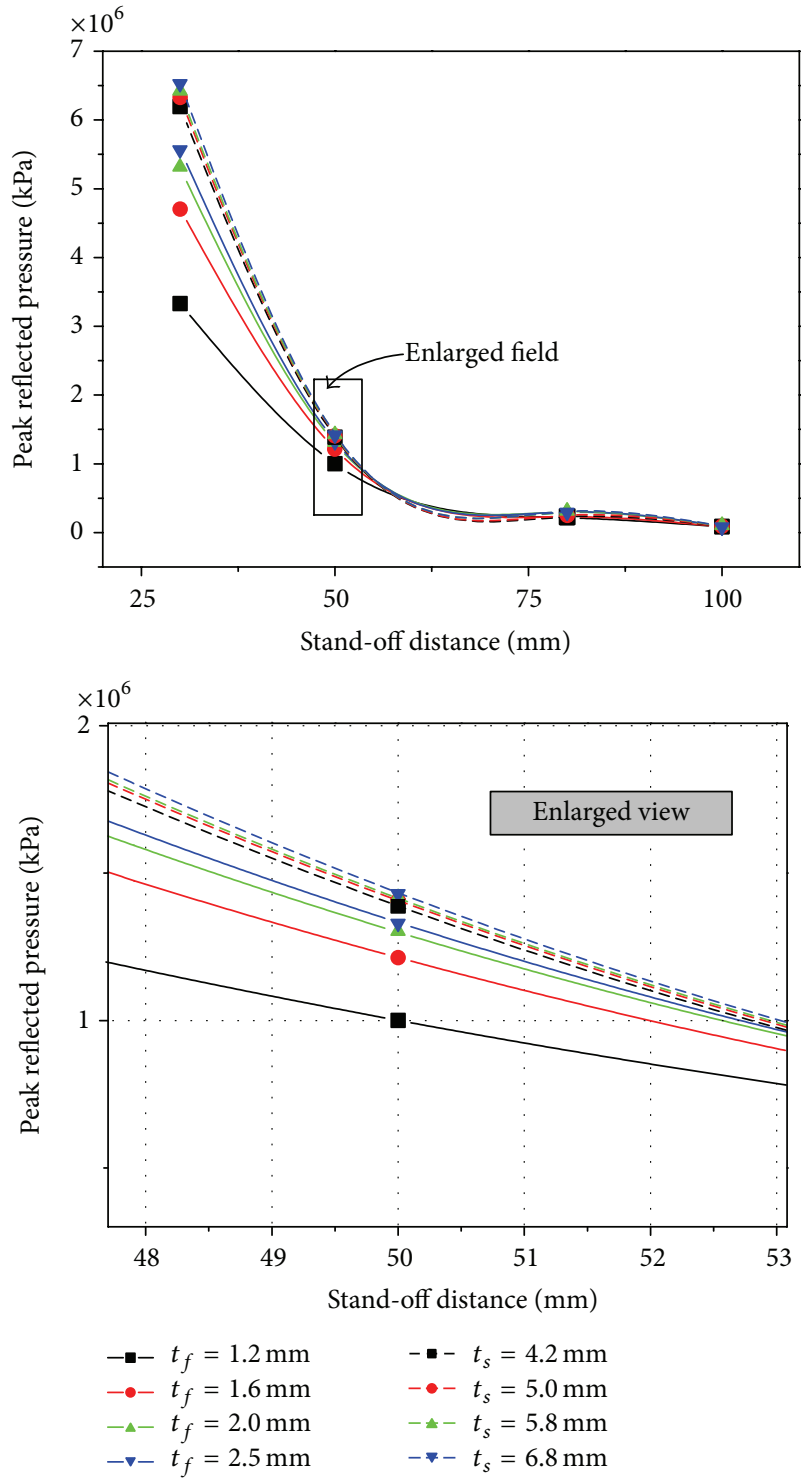

FIGURE 15: Comparison of the peak reflected pressure (near the FSI surface) of sandwich panels and equivalent weight solid plates versus the stand-off distance. For sandwich panels: $t_{c}=1.0 \mathrm{~mm}$ and $l=$ $20 \mathrm{~mm}$.

5.3. Effect of Core Configuration. The core configuration contains the core web thickness, cell size, and relative density of core. All of them play a notable role in the impact mitigation effect of corrugated core sandwich panel.

The peak reflected pressure of sandwich panels with the same face sheet thickness $\left(t_{f}=2.0 \mathrm{~mm}\right)$ but different core web thicknesses $\left(t_{c}=1.0 \mathrm{~mm}, 0.7 \mathrm{~mm}\right.$ and $\left.0.5 \mathrm{~mm}\right)$ and different cell sizes ( $l=20 \mathrm{~mm}, 28 \mathrm{~mm}$ and $40 \mathrm{~mm}$ ) is plotted in Figure 17. At first glance, there is a complete overlap among those peak reflected pressure stand-off distance curves. It is concluded that the variations of the core web thickness and cell size result in a negligible change of peak reflected pressure of the midpoint of front face. However, the core works as a foundation for the front face and simultaneously works as a loading transporter for the back face. The configuration of 


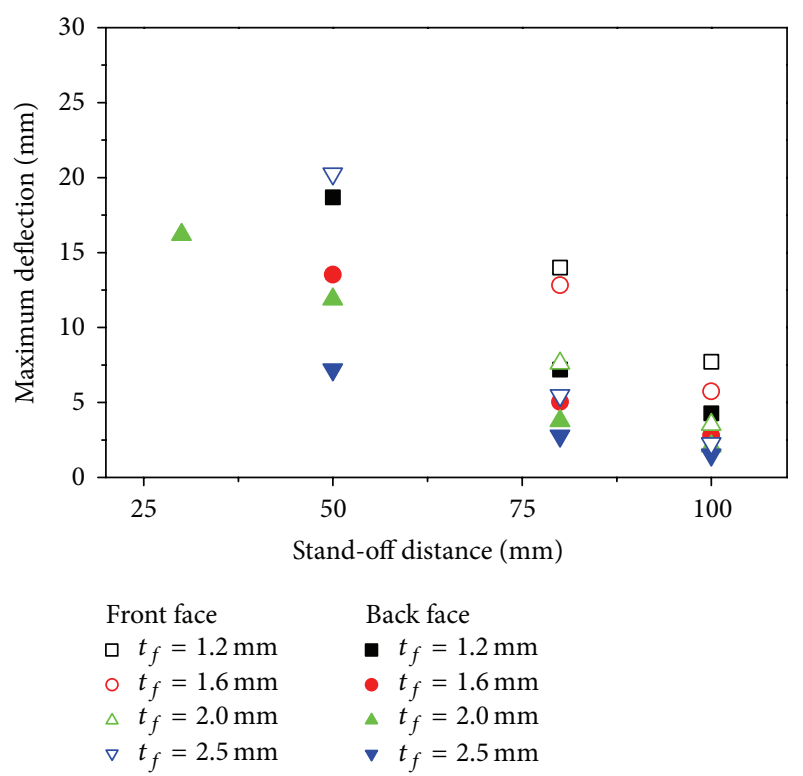

FIGURE 16: Maximum deflections of sandwich panels with same core configuration $\left(t_{c}=1.0 \mathrm{~mm}, l=20 \mathrm{~mm}\right)$.

core can considerably affect the deformation of front face and back face. It can be observed from Figure 14 that, for given face sheet thickness and core web thickness, larger cell sizes (larger core thicknesses for the given inclination angle of $60^{\circ}$ ) result in smaller back face deflections and larger front face deflections. The failure mode of back face is a type of global deformation; the deformation of back face mostly depends on the global bending resistance of sandwich panel. The larger cell sizes have high rigidity in flexure, resulting in a smaller back face deflection under blast loading. However, the failure pattern of front face deflection is a type of central localized failure and is dominated by localized deflection. The maximum deflections of front face are related to the local stiffness of the central field. As the increase of cell sizes, the central field between two core webs becomes weak in stiffness. This is the reason that larger cell sizes result in larger front face deflections. For a given cell size, the effect of core web thickness on deformation is shown in Figure 18. As expected, the deflections of front face and back face reduce with the increase of core web thickness which results in the enhancement of global bending resistance and local stiffness of sandwich panel.

As illustrated previously, the crushing mechanism of core media is mostly dependent on the relative density of core. The relative density of core is determined by the core web thickness and the cell size. However, the relative density of core has no significant influence on the peak reflected pressure, as inferred from Figure 17.

Figure 19 shows the maximum deflections of sandwich panels (S20-25 S20-28, S28-5 S28-8, and S40-1 S40-4) with different cell sizes and core web thicknesses but the same relative density of core $(5.46 \%)$. The variation tendency of front face deflections is not as clear as that of back face. For a

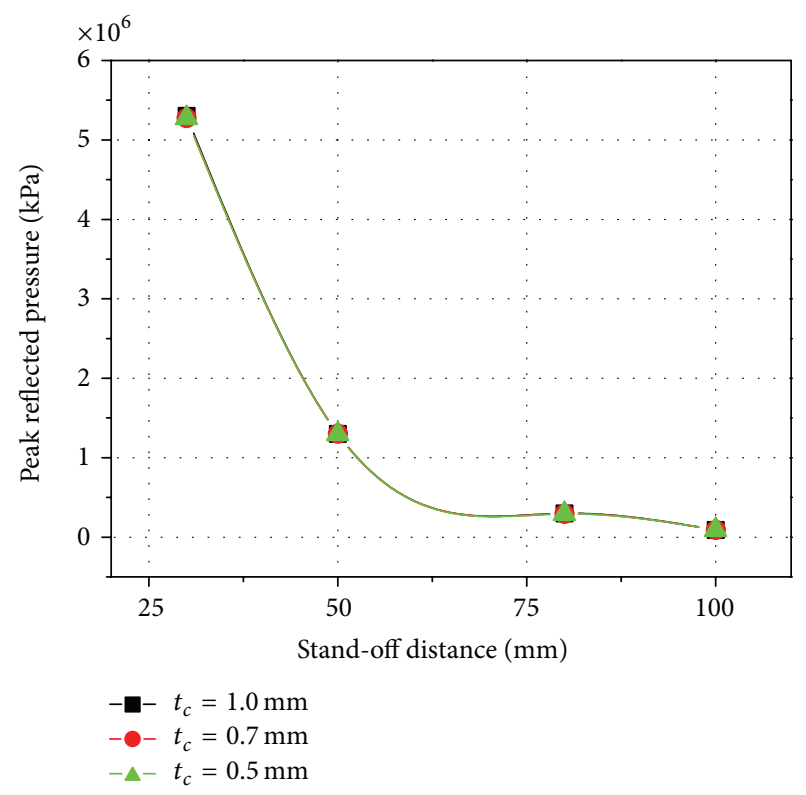

(a)

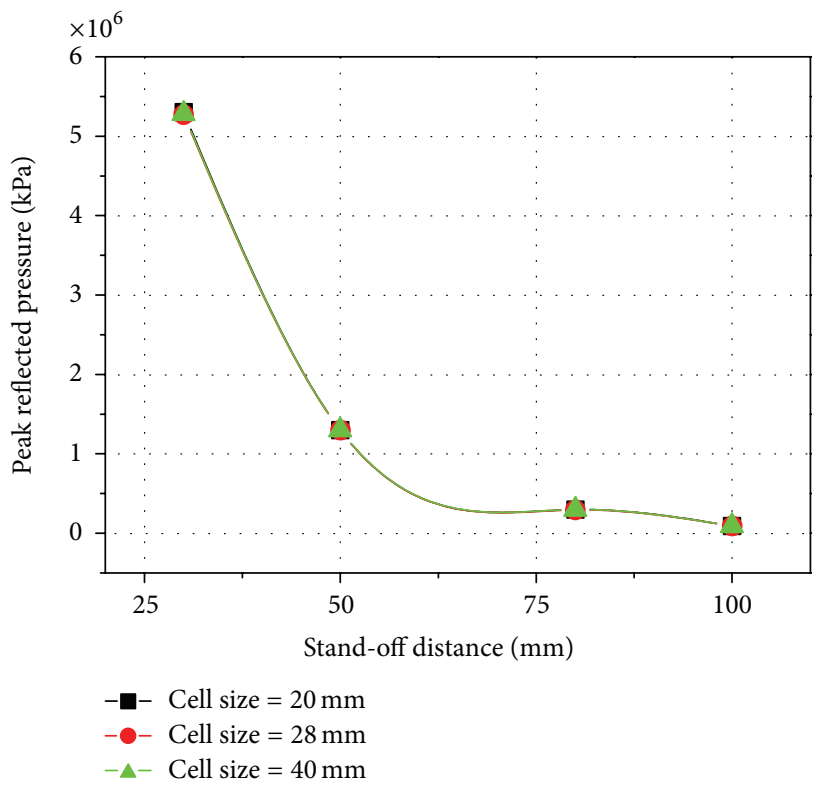

(b)

FIGURE 17: Peak reflected pressure of midpoint of sandwich panels with (a) different core web thicknesses and with (b) different cell sizes.

given relative density, the cell size plays a leading role in the influence of back face deflections.

Figure 20 shows the maximum deflections of back face of three sandwich panels with similar weight (i.e., the equivalent solid plates thicknesses are $5.79 \mathrm{~mm}, 5.85 \mathrm{~mm}$, and $5.89 \mathrm{~mm}$, resp.) but different relative density of core (i.e., $10.35 \%, 7.63 \%$, and $5.46 \%$, resp.) subjected to the same blast loading. It is found that the back face deflections increase with the increase of core relative density, especially at lower stand-off distance. 


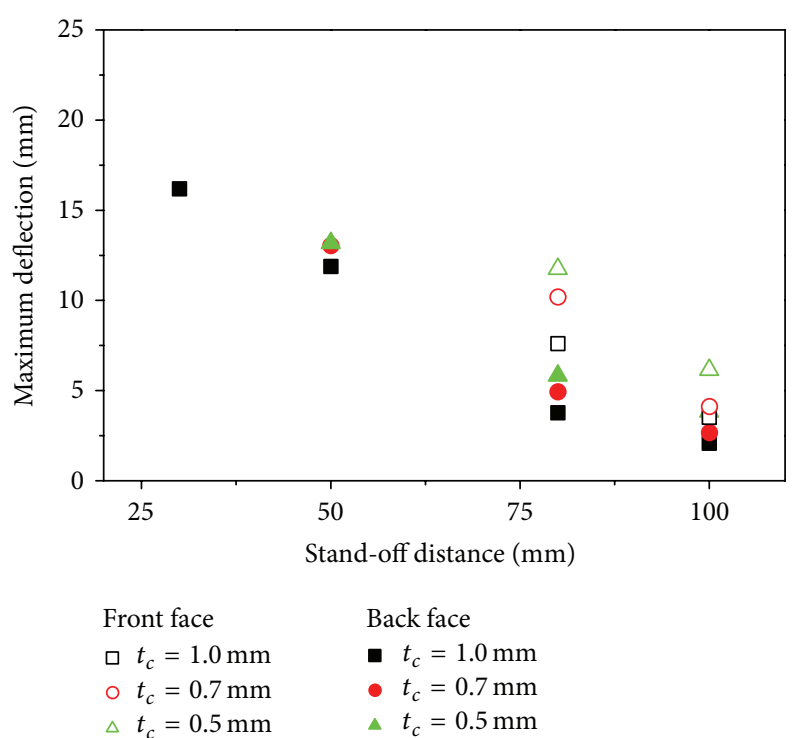

FIGURE 18: Maximum deflections of front face and back face of sandwich panels with different core web thicknesses.

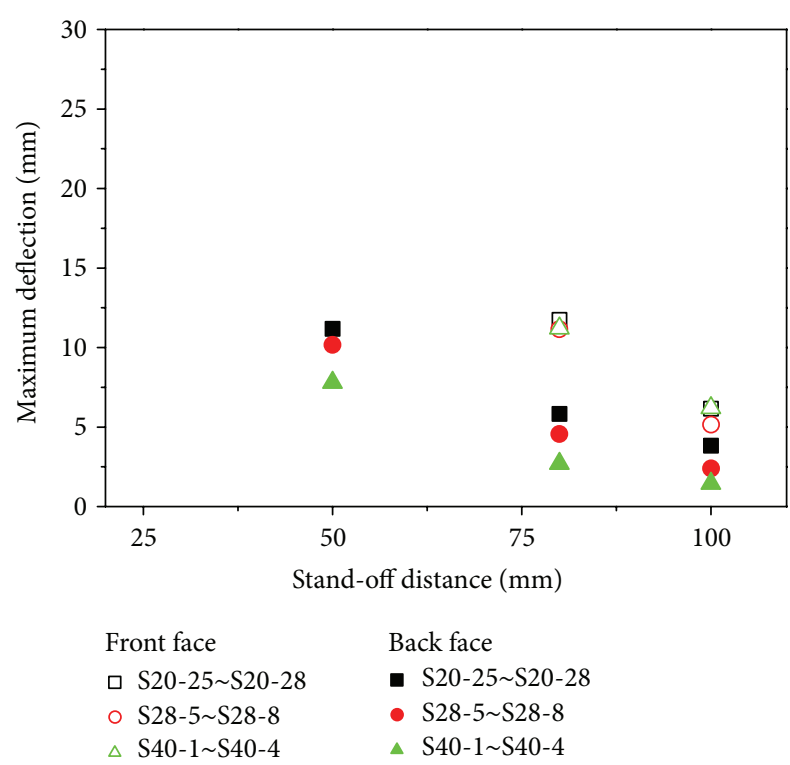

FIGURE 19: Maximum deflections of sandwich panels with the same relative density $(5.46 \%)$.

\section{Conclusions}

A detailed numerical analysis based on fully coupled numerical method is presented, aiming to reveal the interaction between the explosive gas product and sandwich panel. The important role of the nonlinear compression of air medium played in beneficial FSI effect under near-field air blast is revealed by investigating the distributions of shock wave pressure both temporally and spatially. It is concluded that the nonlinear compression effect is significant under nearfield air blast. Under near-field air blast loading, the front face of sandwich panel undergoes a significant local bending

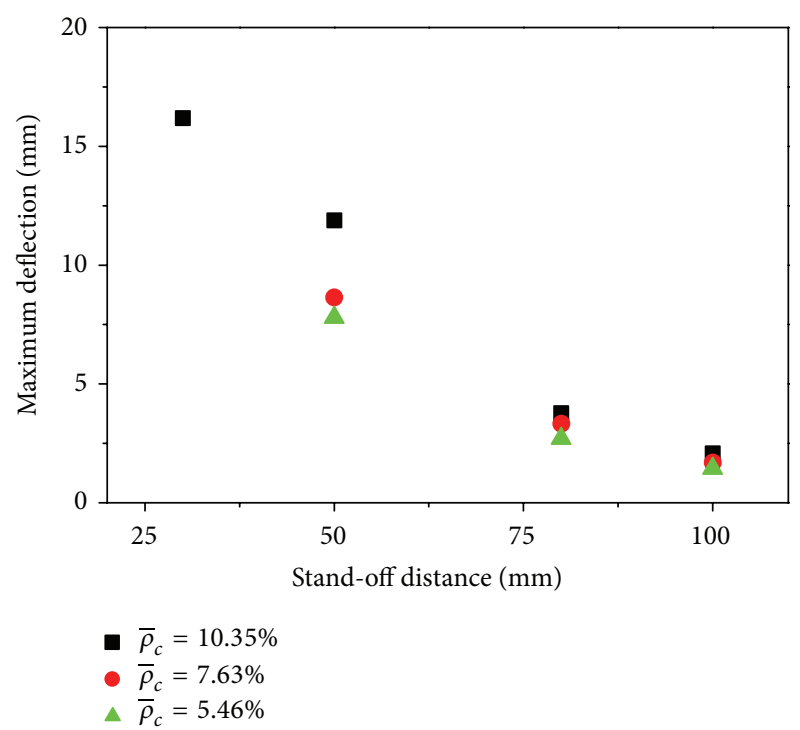

Figure 20: Maximum deflections of back face of sandwich panels with different relative density of core.

deformation which leads to the occurrence of streak type deformation between core webs in the center field, while the deformation pattern of back face is determined by global bending deformation.

The parametric study shows that the failure modes of sandwich panels depend strongly on stand-off distance. And the failure area increases with the decrease of stand-off distance. The benefits of sandwich construction over solid plate to withstand blast loads are clearly evident with lower back plate deflections and lower peak reflected pressures compared with the equivalent weight solid plates subjected to the same load. It is found that those benefits are more evident at lower stand-off distance. As the reduction of face sheet thickness, the benefit of FSI effect of sandwich construction is enhanced greatly and the deflections of sandwich front face and back face increase. The sandwich panels with a light face sheet are more likely to fail. Therefore, it is essential to optimize the configuration of sandwich panel to keep back face from damage failure. The core configuration has a negligible influence on the peak reflected pressure. By adopting larger cell sizes and thicker core webs, the deflections of back faces can be reduced. For a given areal density of sandwich panel, the back face deflections increase with the increase of core relative density.

\section{Conflict of Interests}

The authors declare that there is no conflict of interests regarding the publication of this paper.

\section{Acknowledgments}

The reported research is supported by the National Natural Science Founding of China (under the Contract no. 51209099) and the Supporting Technology Funding of Shipbuilding Industry. The financial contributions are hereby gratefully acknowledged. 


\section{References}

[1] Z. Xue and J. W. Hutchinson, "Preliminary assessment of sandwich plates subject to blast loads," International Journal of Mechanical Sciences, vol. 45, no. 4, pp. 687-705, 2003.

[2] L. Yueming, A. V. Spuskanyuk, S. E. Flores et al., "The response of metallic sandwich panels to water blast," Journal of Applied Mechanics, Transactions ASME, vol. 74, no. 1, pp. 81-99, 2007.

[3] Z. Xue and J. W. Hutchinson, "A comparative study of impulseresistant metal sandwich plates," International Journal of Impact Engineering, vol. 30, no. 10, pp. 1283-1305, 2004.

[4] G. I. Taylor, "The pressure and impulse of submarine explosion waves on plates," in The Scientific Papers of Sir Geoffrey Ingram Taylor. Aerodynamics and the Mechanics of Projectiles and Explosions, G. K. Batchelor, Ed., vol. 3, pp. 287-301, Cambridge University Press, Cambridge, UK, 1963.

[5] N. Kambouchev, L. Noels, and R. Radovitzky, "Nonlinear compressibility effects in fluid-structure interaction and their implications on the air-blast loading of structures," Journal of Applied Physics, vol. 100, no. 6, Article ID 063519, 2006.

[6] N. Kambouchev, L. Noels, and R. Radovitzky, "Numerical simulation of the fluid-structure interaction between air blast waves and free-standing plates," Computers and Structures, vol. 85, no. 11-14, pp. 923-931, 2007.

[7] N. Kambouchev, Analysis of blast mitigation strategies exploiting fluid-structure interaction [Ph.D. thesis], Massachusetts Institute of Technology, Cambridge, Mass, USA, 2007.

[8] F. Zhu, G. Lu, D. Ruan, and D. Shu, "Tearing of metallic sandwich panels subjected to air shock loading," Structural Engineering and Mechanics, vol. 32, no. 2, pp. 351-370, 2009.

[9] K. P. Dharmasena, H. N. G. Wadley, Z. Xue, and J. W. Hutchinson, "Mechanical response of metallic honeycomb sandwich panel structures to high-intensity dynamic loading," International Journal of Impact Engineering, vol. 35, no. 9, pp. 10631074, 2008.

[10] Z. Wei, V. S. Deshpande, A. G. Evans et al., "The resistance of metallic plates to localized impulse," Journal of the Mechanics and Physics of Solids, vol. 56, no. 5, pp. 2074-2091, 2008.

[11] G. N. Nurick, G. S. Langdon, Y. Chi, and N. Jacob, "Behaviour of sandwich panels subjected to intense air blast. Part 1. Experiments," Composite Structures, vol. 91, no. 4, pp. 433-441, 2009.

[12] D. Karagiozova, G. N. Nurick, and G. S. Langdon, "Behaviour of sandwich panels subject to intense air blasts-part 2: numerical simulation," Composite Structures, vol. 91, no. 4, pp. 442-450, 2009.

[13] K. P. Dharmasena, H. N. G. Wadley, K. Williams, Z. Xue, and J. W. Hutchinson, "Response of metallic pyramidal lattice core sandwich panels to high intensity impulsive loading in air," International Journal of Impact Engineering, vol. 38, no. 5, pp. 275-289, 2011.

[14] J. J. Rimoli, B. Talamini, J. J. Wetzel, K. P. Dharmasena, R. Radovitzky, and H. N. G. Wadley, "Wet-sand impulse loading of metallic plates and corrugated core sandwich panels," International Journal of Impact Engineering, vol. 38, no. 10, pp. 837-848, 2011.

[15] V. S. Deshpande, R. M. McMeeking, H. N. G. Wadley, and A. G. Evans, "Constitutive model for predicting dynamic interactions between soil ejecta and structural panels," Journal of the Mechanics and Physics of Solids, vol. 57, no. 8, pp. 1139-1164, 2009.
[16] H. N. G. Wadley, T. Borvik, L. Olovsson et al., "Deformation and fracture of impulsively loaded sandwich panels," Journal of the Mechanics and Physics of Solids, vol. 61, no. 2, pp. 674-699, 2013.

[17] M. Cockcroft and D. Latham, "Ductility and the workability of metals," Journal of the Institute of Metals, vol. 96, no. 1, pp. 33-39, 1968.

[18] S. Lee, F. Barthelat, J. W. Hutchinson, and H. D. Espinosa, "Dynamic failure of metallic pyramidal truss core materialsexperiments and modeling," International Journal of Plasticity, vol. 22, no. 11, pp. 2118-2145, 2006.

[19] D.-G. Ahn, G.-J. Moon, C.-G. Jung, G.-Y. Han, and D.-Y. Yang, "IMPACT behavior of A STS $304 \mathrm{H}$ sheet with a thickness of 0.7 MM," Arabian Journal for Science and Engineering, vol. 34, no. 1, pp. 57-71, 2009.

[20] AUTODYN, Theory Manual Revision 4.3., Century Dynamics, Concord, Mass, USA, 2005.

[21] G. F. Kinney and K. J. Graham, Explosive Shocks in Air, Springer, New York, NY, USA, 2nd edition, 1985.

[22] N. Jacob, K. Y. Chung, G. N. Nurick, D. Bonorchis, S. A. Desai, and D. Tait, "Scaling aspects of quadrangular plates subjected to localised blast loads-experiments and predictions," International Journal of Impact Engineering, vol. 30, no. 8-9, pp. 11791208, 2004.

[23] F. Zhu, L. Zhao, G. Lu, and E. Gad, "A numerical simulation of the blast impact of square metallic sandwich panels," International Journal of Impact Engineering, vol. 36, no. 5, pp. 687-699, 2009. 

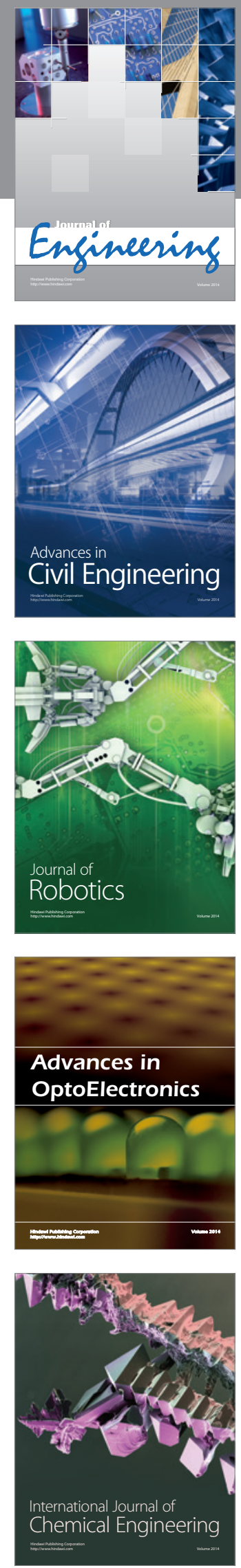

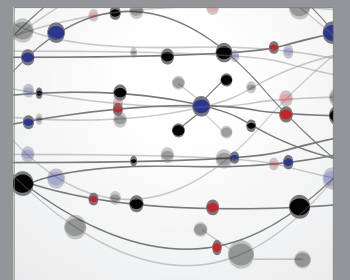

The Scientific World Journal
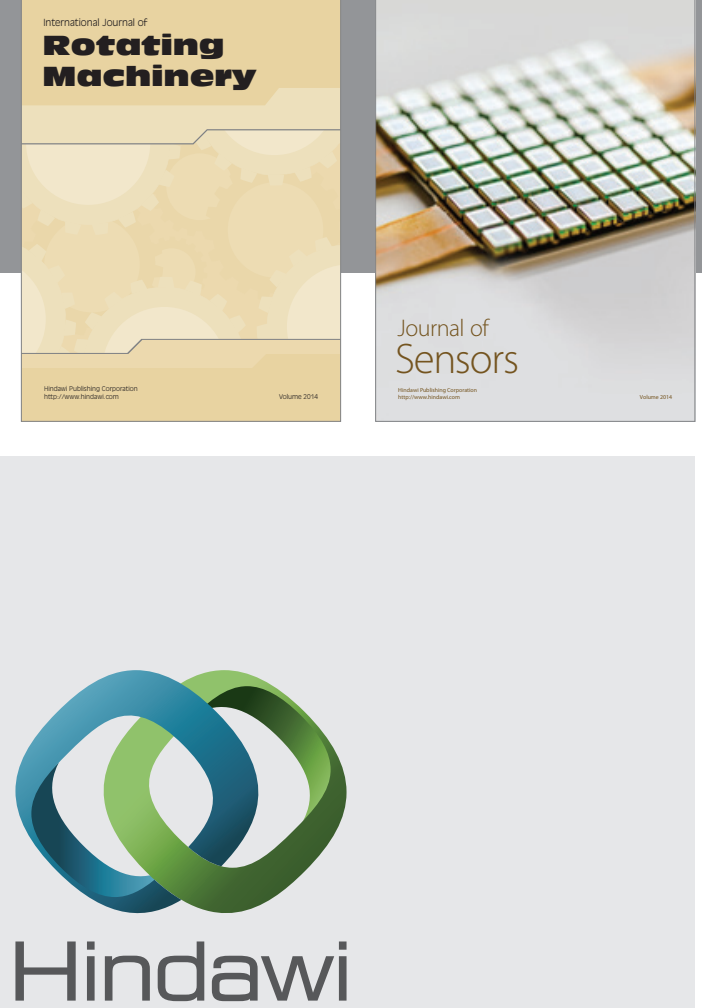

Submit your manuscripts at http://www.hindawi.com
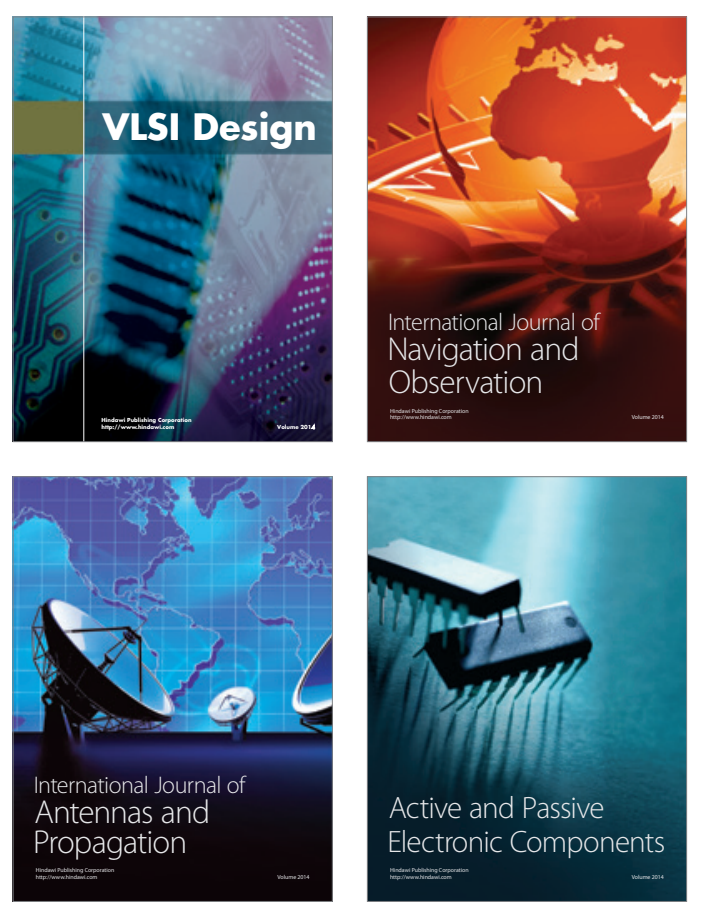
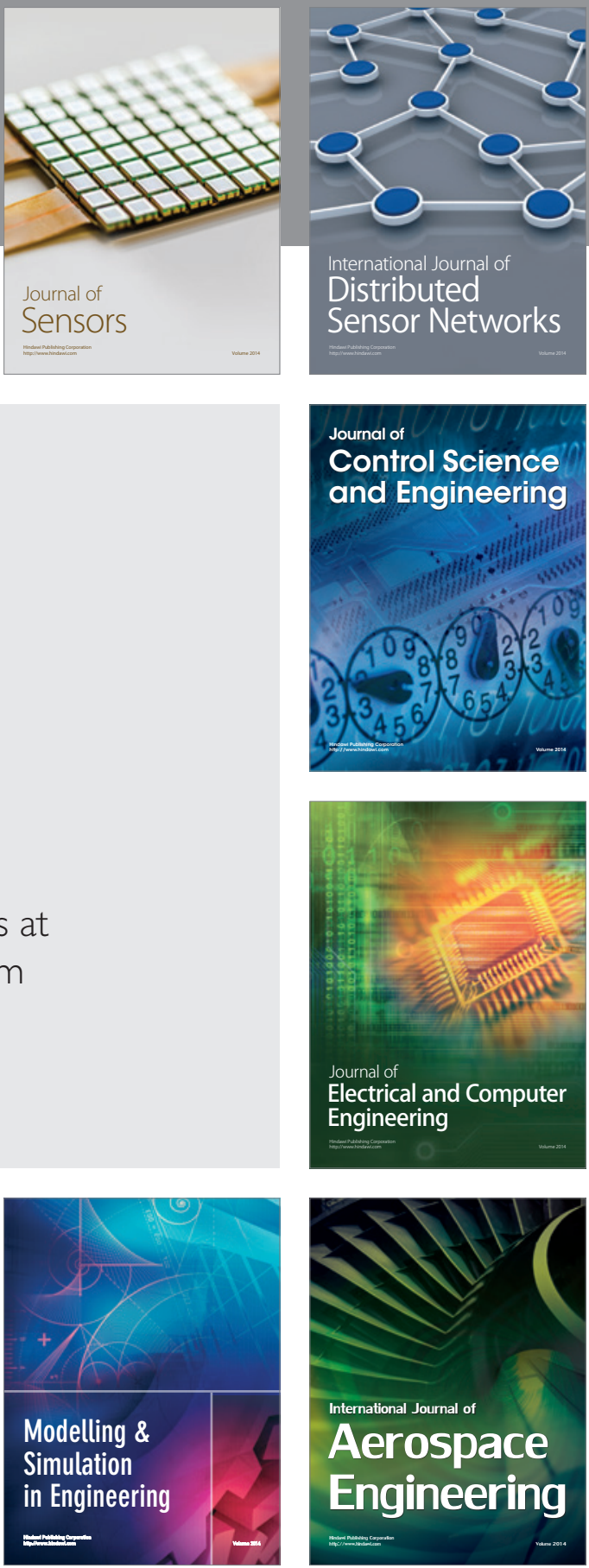

Journal of

Control Science

and Engineering
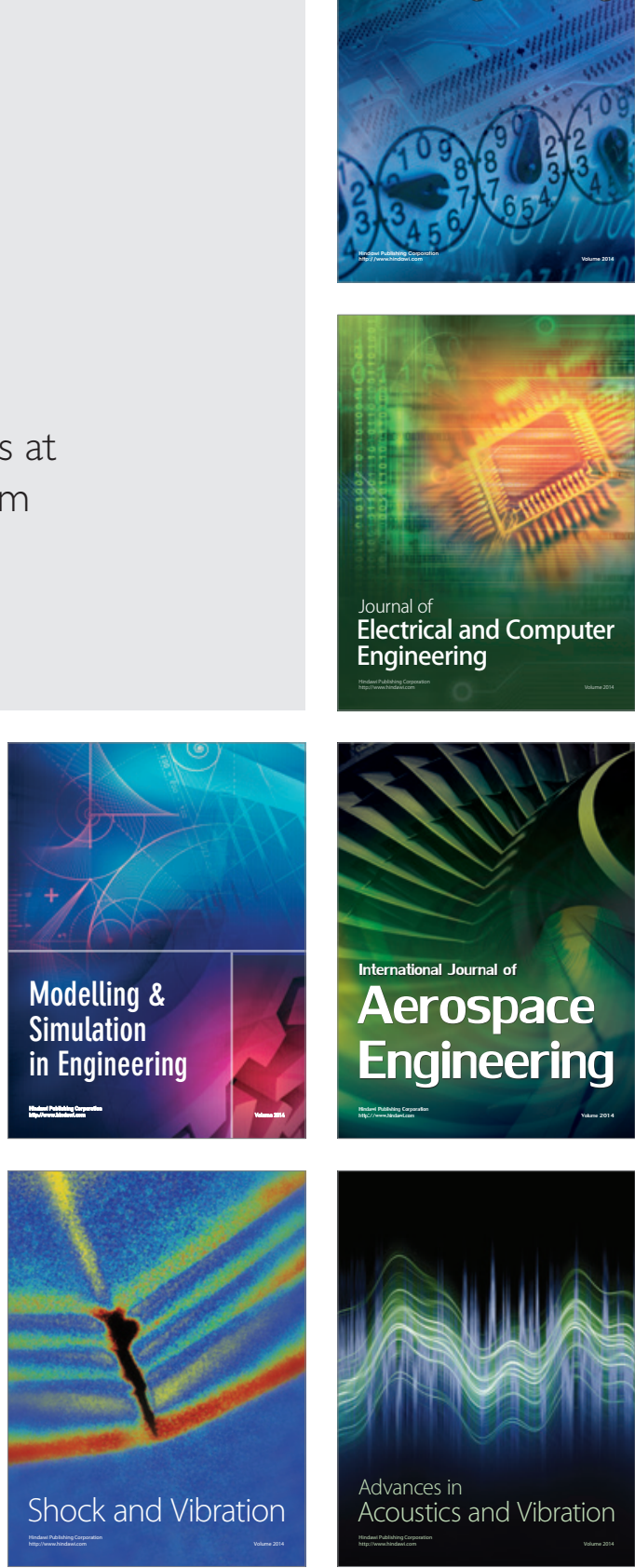